\title{
The Post-Communist Fertility Puzzle
}

\author{
Sunnee Billingsley
}

Received: 22 February 2008/Accepted: 26 March 2009/Published online: 21 April 2009

(C) The Author(s) 2009. This article is published with open access at Springerlink.com

\begin{abstract}
Fertility has unanimously declined across the entire post-communist region. This study explores the variation in fertility trends over time among these countries and assesses to what degree three explanations are applicable: second demographic transition (SDT), postponement transition (PPT) or reaction to the economic crisis. Moreover, on the basis of SDT and PPT theoretical tenets, as well as descriptive evidence, the economic context is hypothesized to be linked to two processes of fertility decline conversely. The results show that no one theoretical explanation is sufficient to explain the complex fertility declines across the entire post-communist region from 1990 to 2003. In some countries, a great part of the decline in fertility occurred before significant postponement of childbearing began, which indicates that the dramatic decline was due to stopping behavior or postponement of higher order births. Postponement of first births, either through PPT or SDT processes, greatly contributed to fertility decline in a small number of countries. Pooled cross-sectional time-series analyses of age-specific birthrates confirm that these two distinct processes are present and show that the economic crisis explanation has explanatory power for declining birth rates. In contrast, logistic regressions show that the likelihood of postponing childbirth increases with improved economic conditions. These results confirm the importance of taking the economic context into account when discussing explanations for fertility decline. More specifically, the results indicate that the severity and duration of economic crisis, or absence thereof, influenced the extent and manner in which fertility declined.
\end{abstract}

Keywords Fertility · Post-communist - Economic crisis · Postponement transition - Second demographic transition

\footnotetext{
S. Billingsley $(\bowtie)$

Department of Political and Social Sciences, Pompeu Fabra Universitat, Ramon Trias Fargas, 25-27, 08005 Barcelona, Spain

e-mail: sunneeellen.billingsley01@ campus.upf.edu
} 


\section{Introduction}

As of 2004, 15 countries of the former Soviet Union (FSU) and Central and Eastern Europe (CEE) have entered lowest-low fertility at least once, ${ }^{1}$ and all FSU and CEE countries have experienced a remarkable decline in fertility since the onset of transition from communism. The driving force behind this decline remains debatable. To date, the literature offers evidence that worsening economic conditions contributed to the decline in fertility (e.g., UN ECE 2000; Cornia and Paniccià 1998; Kohler and Kohler's 2002 macro-data analysis). However, other studies found no evidence in support of the economic crisis explanation (e.g., Kharkova and Andreev 2000; Kohlman and Zuev 2001; Kohler and Kohler's 2002 micro-data analysis). Rather, researchers have turned to demographic theory and argue that the decline is evidence of Lesthaeghe and van de Kaa's (1986) second demographic transition (SDT) (Zakharov and Ivanova 1996; Vishnevskii 1999), while others suggest that the presence of lowest-low fertility in the region can be called a "postponement transition" (Kohler et al. 2002).

This paper makes two arguments: First, different processes underlie the fertility declines across the post-communist region ${ }^{2}$ as well as across the years of transition from communism: postponement of childbearing on the one hand and a decline in higher order births on the other. Research on the declining fertility rates of the postcommunist countries has not adequately distinguished between countries and time periods according to important differences in these underlying processes, which has resulted in a conflation of explanations and obscured the links between applicable theories and discrete empirical situations. The second argument is that both postponement and stopping behavior are differentially linked to the economic context: improving economic conditions is linked to postponement of childbearing and stopping behavior is linked to deteriorating economic conditions.

In this analysis, descriptive analyses do not demonstrate conditions amenable to a SDT, according to its theory, across the entire post-communist region, regardless of the universal presence of some SDT symptoms. Furthermore, postponement of childbirth appears to explain the lion's share of fertility decline in no more than five of the post-communist countries studied here. Although conditions were not conducive to a SDT in the first years of transition from communism in a few countries, substantial economic recovery and postponement of childbirth had begun by the mid-1990s. Regression analyses demonstrate that distinct processes are associated with different countries and that the economic context is related to the

\footnotetext{
1 This paper follows the Kohler et al. (2002) classification of lowest-low fertility as any total fertility rate (TFR) below 1.3. TFR refers to the average number of children a woman would have had, if she lives until the end of her childbearing years and fulfills childbearing according to the current age-specific birth rates.

2 In the descriptive analyses, Armenia, Azerbaijan, Belarus, Bulgaria, Czech Republic, Estonia, Georgia, Hungary, Kazakhstan, Kyrgyz Republic, Latvia, Lithuania, Moldova, Poland, Romania, Russia, Slovakia, Slovenia, Tajikistan, Turkmenistan, Ukraine, and Uzbekistan are included. In the regression analyses, a restricted sample is used for reasons discussed later, in which the majority of the Central Asian Republics are excluded. Throughout the entire paper, countries of the former Yugoslavia (excluding Slovenia) and Albania are not discussed due to missing data; nor is the former East Germany included for reasons also discussed later.
} 
specific process that drove each decline in fertility. Having countries in the sample that experienced both processes of fertility decline as well as both extremes in economic contexts strengthens these findings.

A few limitations of this study must be acknowledged. First, the task of determining whether postponement of childbirth is due to a postponement transition (PPT), associated with economic uncertainty, or rather the SDT, associated with increased opportunities, value shifts and economic growth, is not attempted here. Rather, the study attempts to identify whether and when either one is a possible explanation. Distinguishing between these two underlying mechanisms of postponement requires a more fine-tuned instrument than a macro-data analysis. This research operates at the macro-level to supplement the micro-data research that is more common in the literature and to offer a contextual analysis of the conditions under which 1) fertility was likely to decrease to a greater degree and 2) significant postponement more likely to occur. Not only is an aggregate analysis especially appropriate when studying transitions due to macro-level changes, individual experiences are linked to factors operating in the larger institutional context and not influenced solely by micro-level factors (Spielauer et al. 2005).

The second limitation is that this analysis is restricted to analyzing short-term causes of fertility decline. The comprehensive cultural and institutional changes that occurred during the latter half of the twentieth century across the region are assumed to have had an impact on fertility behavior. However, clarification is still needed on possible short-term causes such as the role of the economic crisis.

This paper contributes to the debate by systematically reviewing both causal and outcome indicators in light of what we would expect to see given the most popular theoretical explanations. Furthermore, it addresses the recent competing explanation of a PPT, as well as links postponement explicitly to the economic context and explains the decline beyond what postponement can account for. To the best of my knowledge, no other research has attempted to comprehensively discuss these explanations and consider their connection to economic contexts, either theoretically or empirically, even though economic conditions are either an implicit or explicit part of each explanation. The arguments posited in this paper are, however, implied in existing literature, particularly in Sobotka's $(2002,2003)$ work in which he found evidence of two distinct fertility trends within the region. He also found some evidence of a positive association between mean age at first birth and improved economic conditions. This paper seeks to confirm the opposite relationship as well, in regards to a decline in age-specific fertility rates, and to more concretely tie empirical findings to disparate theoretical strands in the literature that have not been considered comprehensively. This study therefore contributes to the literature on the post-communist fertility decline, but also to literature on fertility declines more generally since it has relevance to SDT and PPT theories. Moreover, this study also covers a range of post-communist countries and years beyond what is included in other analyses. A final unique contribution of this paper is that it explicitly analyzes the complementarity between the economic context and different processes of fertility decline.

In the next section, the literature on fertility decline is discussed and economic changes in the post-communist region after the fall of the Soviet Union are briefly 
summary. In the third section, descriptive analyses demonstrate important differences among the post-communist countries and the plausibility of different explanations. The fourth section discusses the analytical models and results of regression analyses that determine the links between economic conditions and both fertility decline and postponement. The fifth section briefly discusses the findings and concludes.

\section{Review of Literature and the Post-Communist Context}

The debate in fertility research of developed countries currently involves two major theoretical perspectives: those that focus on ideational forces and those that focus on economic forces. Lesthaeghe and van de Kaa's (1986) SDT leads the ideational literature. Lesthaeghe and Surkyn (2004) argue that a desire for self-actualization has become predominant and was fueled by three revolutions: (1) a contraceptive revolution, which permits postponement of childbearing; (2) a sexual revolution, which broke the boundaries that kept sexual activity within marriage; (3) a gender revolution, which allowed women to no longer be subservient to men or biology. All three of these revolutions combined re-orientated values and were said to occur "during the peak years of economic growth" (p. 5). The SDT theory dictates that families will gradually become smaller due to greater individualism and post-materialism, which are associated with increased urbanization and postindustrialization. Lesthaeghe and Neidert (2006, p. 669) further describe the forces at work as "not solely the outcomes of changing socioeconomic conditions or rising female employment, but equally the expression of secular and antiauthoritarian sentiments of better-educated men and women who held an egalitarian world view, placed greater emphasis on Maslow's (1954) 'higher order needs' (i.e., self-actualization, individualistic and expressive orientations, need for recognition), and, to use Inglehart's term (1990), had stronger 'postmaterialist' political orientations." The reaction to these forces includes a list of changes in life course events of young adults, including postponement of union formation and childbearing, as well as increased non-marital cohabitation and childbirth. The resulting demographic outcome is fertility well below population replacement level.

Demographic research has primarily concentrated on the symptoms of SDT rather than the causal elements within the theory. This strategy is sound when research involves OECD countries in which continued economic growth and stability are given conditions. Indeed, the references to both Maslow and Inglehart indicate a stage of personal evolution that is conditional upon material needs no longer being the main focus in life. This ranking of needs is clearly stated by Lesthaeghe and Surkyn (2004, p. 8), where they argue that Maslow's (1954) higher order needs can only be expressed once material preoccupations end and financial security is established. However, in many national contexts, economic conditions may be quite different.

Had the high hopes for market transformation been unanimously realized after the breakdown of the Soviet Union, the post-communist fertility narrative might have nicely paralleled the scenario involving affective value shifts as described. The 
elimination of almost complete redistribution would have resulted in more people being able to accumulate wealth and realize individual desires, expression, and lifetime goals through greater autonomy and increased consumption choices. While the break with totalitarian regimes provided further opportunity for greater individualism, it also cohered with the anti-establishment sentiments that have historically brought about increasing heterogeneity in the timing of major life course events. However, the restructuring of the communist economies and governments, in many cases, resulted in economic crises that may have prohibited ascension to post-materialism and self-actualization.

Not only was the macro-environment unstable, breeding uncertainty, but for the first time in the collective memory of individuals across the region, severe poverty engulfed millions (World Bank 2000; Klugman et al. 2002). Income inequality also grew: the average Gini coefficient in the Commonwealth of Independent States (CIS) rose from 0.26 in the late 1980 s to 0.43 , whereas in CEE the change was from 0.25 to 0.30 (UNICEF 2001). Not only did real wages fall in the first years of the transition, but wages were neither always paid in full nor on time (Gimpelson 2001). But given the uncertainty of finding a new job and that social benefits were often provided by the enterprise themselves, employees continued to work for drastically cut wages (Blanchard 1997). In the midst of these changes inflation, and in many countries hyperinflation, occurred. Changes in the consumer price index reveal that almost all of the FSU countries' annual price index increased $>1000 \%$ during the 1990s. Only Czech Republic, Hungary, Poland, Slovakia and Slovenia avoided inflation in the triple digits. Under these conditions of increased poverty and inequality, as well as decreased consumption power, conditions do not appear to have been amenable for a postmaterialist value shift to have occurred in many countries.

Most prominent in the economic discussion is Becker's (1960, 1981; Hotz et al. 1997) micro-economic theory of the family. The economic theory of fertility can be summarized as focusing on the costs of children, which are mediated by household income. Costs are considered both directly, in which the benefits of a child are weighed against the costs, and indirectly, which includes costs related to lost opportunities. Not surprisingly, widespread economic deterioration during the transition from communism encouraged an intuition that the economic crisis might be related to declining fertility in the region. Indeed, researchers have paid explicit tribute to the transition experience by directly linking the post-communist transition and the correlated economic crisis to the decline in fertility. Cornia and Paniccià (1998) found a relationship between economic conditions, as well as family related services and policies, and fertility for the early years of the transition. Their results confirm the importance of the loss of resources that was brought about by structural change. The UN Economic Commission (2000) for Europe found that the decline in income put downward pressure on fertility for ten post-communist countries from 1989 to 1998.

Other researchers focused on explanations related specifically to the transition from communism to capitalism. Sobotka (2002) argues that the "socialist greenhouse," which encompasses a broad range of socialist institutions from the labor market to family/work conciliation policies, artificially kept fertility rates high during the decades in which they would have declined, as in the case of Western 
Europe. Thornton and Philipov (2007) add a new perspective by viewing general changes in this region through the lens of developmental idealism. Similar to the tenets of SDT theory, they argue that norms have shifted in the region; in this case however, the shift is due to adopting norms and behaviors of a model that is perceived as more modern and successful such as the Western European and North American model. Frejka (2008) sidesteps the issue of crisis versus culture in his recent essay by claiming that both economic and ideational explanations are part and parcel of the main explanation, which is broadly the transition to capitalism. His argument allows both frameworks to coincide in our understanding of the fertility decline-as well as numerous other factors that have as of yet been unaccounted for (welfare state change, increased consumerism, etc.). However, other researchers (e.g., Zakharov 2008) clearly still argue against the validity of the economic crisis explanation and argue in favor of the SDT explanation.

Another valuable contribution by Frejka (2008) is his discussion of the ambiguity of the economic crisis explanation. He claims that "by default, economic determinants were understood to fall within the 'crisis' category" (p. 161). He also conceded the difficulty of separating those factors that are solely related to crisis from those traditional economic factors that would operate in a stable economy (p. 164). For example, "competition in the labor market, job insecurity, and rising costs of children" (p. 160) are all economic factors associated with capitalism in general and can all be studied discretely in that context. But in the case of economic crisis, we would expect these myriad economic factors to be at work simultaneously. Most simply, the economic crisis explanation might be understood as a rendition of Becker's direct cost mechanism insofar as we focus on the dramatic devaluation and loss of resources during the transition. This mechanism already has been contextualized, as in the work of the Myrdals' (Myrdal and Myrdal 1934, summarized in English in Gustafsson 2002) Crisis in the Population Question in which they argue that during the Great Depression people sought to have the highest standard of living possible to them and that when the costs of childbearing were too high, fertility continued to decline. Another contextual explanation is Easterlin's (1976) thesis: a conflict between aspirations and resources will reduce the willingness of a couple to have children. Easterlin grounds aspirations in terms of "relative affluence," which refers not to the affluence of other people in a cohort, but to the affluence of a person's family of orientation. If current resources cannot sustain the aspirations an individual has developed over time, childbearing is limited. This perspective may be particularly applicable to post-communist countries, considering that during transition to a market economy the bottom dropped out of previously stable economic terrain.

Exacerbating the economic crisis was the cut in social spending across many post-communist countries. An important omission in this paper is a discussion on the impact of deteriorating state support to households during transition. Because there is extensive variation in levels of support not only among the countries but within each country over time, this factor requires its own analysis. Suffice to say that the loss of state and firm-sponsored family services (Fajth 1999) may have greatly increased reconciliation difficulties between work and family roles as well as opportunity costs. 
Although the relationship between Becker's opportunity costs and declining fertility usually accompanies increased female labor force participation, the transition saw a retreat in women's labor force participation as well as an overrepresentation of women among the unemployed (European Foundation 2005). Economic uncertainty was likely rampant during transition (Bhaumik and Nugent 2002; Kreyenfeld 2005). Ranjan (1999) models the relationship between fertility behavior and income uncertainty in the context of the FSU and CEE countries; this study demonstrated that postponing fertility until a later time is optimal during times of economic uncertainty due to the irreversibility of the decision. Rindfuss et al. (1978) found that uncertainty due to social change in general can also play a role in fertility decisions by looking at the fertility rates of white and black women in the segregated South of the US after the Brown versus Board of Education ruling in 1954 de-segregated the school system. They found an immediate decrease in births following this ruling. Finally, other causal mechanisms that have been the focus of micro-level research such as social capital (Bühler and Philipov 2005; Philipov et al. 2006), social anomie (Philipov et al. 2006), and specific coping strategies such as extra sources of sustenance (Bühler 2004) and informal work situations (PerelliHarris 2006) also may fit within the broader economic crisis explanation. Given these various arguments connecting economic conditions to fertility behavior, and since it is true that economic conditions were related to both the crisis and market reform, this paper explicitly considers the economic explanation as encompassing the various economic explanations of fertility decline. In keeping with this purpose is the decision to analyze economic and fertility changes at the aggregate level rather than at the micro-level, which would be more appropriate to assess the contribution of single economic factors discretely.

A recent theoretical addition to the debate over low fertility rates, which bridges the literature on post-communist demographic studies and research on lowest-low fertility in Europe, is Kohler et al.'s (2002) study. They pooled European and formerly communist countries that have entered lowest-low fertility and found evidence of a "postponement transition" (PPT). At the time of their analysis, 3 countries in Southern Europe, 5 in CEE and 6 in the FSU had lowest-low fertility levels. They found this low TFR level to be due to postponement in childbearing, which distorts the TFR and is a rational reaction to uncertainty originating in the labor market. Moreover, at the aggregate level, changes in the timing of childbirth and lower quantum were found to be reinforcing, due to feedback effects and institutional incentives. This paper is notable in the context of the current research for two reasons: (1) the authors propose a causal mechanism behind postponement that is substantively different than the causal mechanism behind postponement in the SDT theory, and; (2) by pooling Southern European countries with FSU and CEE countries, the authors are implicitly proposing that declines in the latter countries are not particular to the experience of transition from communism or severe economic crisis, but only to more general economic uncertainty. The extent to which this proposed framework is a major competing explanation is debatable, but its presence in the debate is not (See, e.g., Frejka and Sardon 2003).

The literature, therefore, yields three distinct arguments to explain fertility decline in the post-communist countries: SDT, PPT and economic crisis. Table 1 
provides an outline of elements that ought to cohere according to the specific tenets of these frameworks. The main points relevant to these three explanations are summarized, as well as their commonalities and differences. SDT is a theory of cultural change to explain the presence of permanent below-replacement level fertility or postponement of childbearing. PPT is a theory of rational action and feedback effects to explain period fertility levels that have fallen to lowest-low levels. The economic crisis explanation encompasses economic theories of fertility behavior and has arisen as a somewhat ad-hoc explanation in response to the events in the post-communist region. The main motivation behind SDT is self-realization (Lesthaeghe and Surkyn 2004, p. 3). The main motivation behind PPT is delaying long-term decisions due to uncertainty. The main motivation in the economic crisis explanation is preoccupation with material needs, which is played out according to many economic explanations. Both SDT and PPT manifest themselves in fertility patterns through significant postponement of childbirth, whereas we would expect to see less postponement of childbirth and more stopping behavior according to the economic crisis explanation. In other words, people may have chosen to have fewer children than they would have had if the economic crisis did not occur because securing material needs became a higher priority than fulfilling a desired family size. According to the PPT theory, people may choose to have fewer children, but more importantly, they wait to have children, as a rational reaction to economic uncertainty. Finally, SDT links postponement behavior to increased opportunity for self-actualization due to the increasing array of options and affective value shifts that accompany economic stability and growth.

Two more commonalities exist between SDT and PPT that are not reflected in the table. First is the importance of adaptation effects- "life course choices feed back onto value orientations, either to reinforce or to alter them" (Lesthaeghe and Surkyn 2004, p. 13) —or social feedback effects (Kohler et al. 2002), which suppress already low fertility and may be distinct from the motivations for the original decline. Both of these elements offer explanations that may explain why fertility has not recovered to pre-transition or pre-crisis levels after some countries have experienced economic recovery. Moreover, they allude to the possibility of one driving force being replaced by another over time, which is another reason this analysis takes a "when/when not" perspective rather than an "either/or" perspective. For example, it may be that the economic crisis explanation explains the decline in fertility only until the point at which economic recovery relieved the pressure on individuals and, henceforth, normative or cultural change-brought

Table 1 Theoretical diagram of explanations for fertility decline

\begin{tabular}{llll}
\hline & $\begin{array}{l}\text { Economic crisis } \\
\text { explanation }\end{array}$ & Postponement transition & $\begin{array}{l}\text { Second demographic } \\
\text { transition }\end{array}$ \\
\hline $\begin{array}{l}\text { Economic context } \\
\text { Fertility process }\end{array}$ & $\begin{array}{l}\text { Crisis } \\
\text { Stopping behavior/postponement } \\
\text { of higher order births }\end{array}$ & $\begin{array}{l}\text { Transition/stability } \\
\text { Postponement of childbirth }\end{array}$ & $\begin{array}{l}\text { Stability } \\
\text { Postponement } \\
\text { of childbirth } \\
\text { Motivation behind } \\
\text { family-planning }\end{array}$ \\
\hline
\end{tabular}


about by lower fertility and broader social changes-became the driving force (Lesthaeghe and Surkyn 2002).

The second commonality is the emphasis placed on tertiary education in SDT and PPT. In SDT theory, women's choices and autonomy increase as female tertiary education enrollment increases, leading to a disruption of women's traditional roles in the family. Prolonged education becomes a delaying force for major life course events such as family formation as well as an influential force on values. PPT theorists, however, argue that with labor market uncertainty, higher education enrollment increases not only as an investment strategy for labor market success, but also as an alternative strategy to entering the job market when youth unemployment is high (Kohler et al. 2002). As we would expect, the authors found that tertiary education enrollment for women increased the most in those countries in which significant postponement of first birth occurred. But because the authors point out that the economic crisis might encourage continued education rather than labor market entrance while also suppressing fertility, the role of higher education in fertility decline becomes ambiguous. Hence, although higher education enrollment rates will be commented upon in the descriptive analyses, these rates are not discussed further in terms of major explanatory forces of declining fertility.

A final consideration in distinguishing between shifts in fertility behavior and their respective explanations is why the economic crisis would not also impact the decision to have a first child, which would likely lead to postponement. Indeed, PPT theory argues that economic uncertainty would induce postponement of the first birth. The literature on the post-communist region does not provide a link between continued early childbearing and the economic crisis. However, Perelli-Harris (2005) found that women still had the first child at a young age in Ukraine because of traditional norms. This evidence presents a counterfactual to the SDT theory, in which we see that although fertility decreased dramatically, ideational change has not been paired with postponement. One other theoretical basis for understanding the relationship between continued early childbearing and economic crisis is Friedman et al.'s (1994) "uncertainty reduction strategy" in which women who experienced obstacles to alternative life paths continued the traditional early childbearing pattern because it provided certainty during an uncertain time.

\section{Characterizing Fertility Decline in the Former Eastern Europe and Soviet Union}

The first purpose of this paper is to enhance our understanding of the compatibility of major explanations or theories with empirical evidence, keeping context in mind. The descriptive analysis is structured in response to the three major competing explanations: SDT, PPT and economic crisis. The first part therefore refers to the likelihood of SDT in this region. The second part focuses on whether significant postponement of childbirth occurred in each country, whereas the third part examines the timing of postponement onset and its contribution to overall fertility decline. These three sections offer descriptive information that allow us to establish 
where and when SDT conditions occurred, where and when it appears likely that a PPT may have been in force, and where and when the economic context and no significant postponement of childbirth rules out SDT or PPT explanations.

To put the recent fertility changes in a historical context, Table 2 shows changes in fertility behavior over the last decades. TFR almost halved during this time, with the majority of the decrease taking place after the end of the Soviet Union. What this table fails to convey, due to simplicity, is that many countries experienced small increases in TFR during the 1980s. This is thought to be due to pro-natalist policies and programs that were implemented during the 1980s to increase fertility (Zakharov and Ivanova 1996; UN ECE 2000).

Many similar demographic changes occurred across countries in the sample. For example, the average age at first marriage increased during the 1990s in every country. Adolescent live births decreased in every country, even though many countries experienced a brief increase in adolescent births during the first few years of transition. Also worth noting is the considerable increase in live births to nonmarried women. The average increase in the share of non-marital births to total births across the region was $20 \%$, with Estonia leading the ranks with a $33 \%$ increase and Turkmenistan with the lowest increase of $7 \%$ (if we exclude the Central Asian Republics, the lowest increase was found in Ukraine at $10 \%$ ). Not

Table 2 TFR from 1970 to 2000

Source: TransMONEE 2006 Database, UNICEF IRC, Florence, and the Council of Europe's Demographic Yearbook (2003)

\begin{tabular}{lllll}
\hline Country & 1970 & 1980 & 1990 & 2000 \\
\hline Armenia & 3.2 & 2.3 & 2.6 & 1.1 \\
Azerbaijan & 4.7 & 3.2 & 2.6 & 1.9 \\
Belarus & 2.4 & 2.0 & 1.9 & 1.3 \\
Bulgaria & 2.2 & 2.0 & 1.7 & 1.3 \\
Czech Republic & 1.9 & 2.1 & 1.9 & 1.3 \\
Estonia & 2.2 & 2.0 & 2.1 & 1.4 \\
Georgia & 2.6 & 2.3 & 2.2 & 1.5 \\
Hungary & 2.0 & 1.9 & 1.8 & 1.3 \\
Kazakhstan & 3.4 & 2.9 & 2.7 & 1.8 \\
Kyrgyzstan & 4.9 & 4.1 & 3.6 & 2.4 \\
Latvia & 1.9 & 2.0 & 2.0 & 1.2 \\
Lithuania & 2.4 & 2.0 & 2.0 & 1.4 \\
Poland & 2.2 & 2.3 & 2.0 & 1.3 \\
Moldova & 2.6 & 2.4 & 2.4 & 1.3 \\
Romania & 2.9 & 2.4 & 1.5 & 1.3 \\
Russian & 2.0 & 1.9 & 1.9 & 1.2 \\
Slovakia & 2.4 & 2.3 & 2.1 & 1.3 \\
Slovenia & 2.1 & 2.1 & 1.5 & 1.3 \\
Tajikistan & 5.9 & 5.6 & 5.1 & 3.1 \\
Turkmenistan & 6.0 & 4.9 & 4.2 & 2.3 \\
Ukraine & 2.1 & 2.0 & 1.9 & 1.2 \\
Uzbekistan & 5.7 & 4.8 & 4.1 & 2.6 \\
\hline & & & &
\end{tabular}


surprisingly, the marriage rate fell across the board during the transition. ${ }^{3}$ All of the findings thus far systematically describe indicators of SDT. Moreover, some postponement of childbirth can be observed in increases of mother's age at first birth, which is a crucial symptom of a SDT as it relates to fertility.

Despite the smoking gun pointed towards SDT, these symptoms could be related to a PPT due to economic uncertainty. Conversely, they could also indicate a disruption of most life course events brought about by the social and economic disruption. Research on single countries has pointed to the fact that many symptoms associated with SDT may in fact be driven by other forces (see, e.g., Perelli-Harris 2005 on Ukraine; Gerber and Cottrell 2006 on Russia; Rotariu 2006 on Romania). Establishing the link between demographic change and SDT requires more than simply the presence of interconnected demographic changes or a logical sequencing of these changes. ${ }^{4}$ Rather, we must be able to connect the context in which these changes occur, or actual ideational change, to demographic changes. While it is not possible to study ideational change for many of the countries in the region, we can assess the conditions under which SDT is argued to occur. Therefore, I offer other information to characterize the context in which these changes occurred and shed light on whether SDT can compete in this context with the PPT thesis. Specifically, the contextual indicator that I argue offers a powerful clue is whether mortality was under control at the time of fertility decline.

Mortality rates are relevant to SDT theory; according to van de Kaa (2002), "In the second transition fertility and mortality are both strongly influenced by normative changes in advanced industrialized societies" (p. 8). He expected the value shifts that take place in a SDT to improve health behavior, but that improvements in longevity would probably lag behind changes in fertility rates. We have yet to see this improvement in many post-communist countries and van de Kaa's statement can hardly be considered an accurate characterization of the post-communist context in which mortality rates significantly deviated from long-term trends (Cornia and Paniccià 1998; Shkolnikov et al. 1998), despite incremental increases in some mortality rates since the 1960s (Shkolnikov et al. 2004). However, no direct relationship between mortality and fertility can be assumed since the greatest increase in mortality during the transition from communism occurred for men past the age of usual family formation (Shkolnikov et al. 2004). The increase in mortality rates during the concurrent decline in fertility is not important solely because it defies SDT theorists' expectations, but also because it qualifies each country's transition experience. Fertility declines that have led to below replacement level fertility and currently to lowest-low fertility have historically occurred in high-income countries, characterized by a nation-wide "post-materialist" individualistic state that leads to SDT (Lesthaeghe and Neidert 2006), a context in which longevity is on the rise. Therefore, it is a fair assumption that mortality levels would continue to improve or at least maintain stable levels under conditions that would be suitable to a SDT.

\footnotetext{
${ }^{3}$ For more information about these widespread changes, see Sobotka's (2002) detailed work on many of the post-communist countries.

${ }^{4}$ See Sobotka et al. (2003) for a discussion on the three conceptualizations of SDT they discern in the literature.
} 
Longevity did not increase for the majority of the post-communist countries and, in fact, mortality rates declined along with fertility in only a few cases. Figure 1 displays concurrent mortality and fertility trends to demonstrate how the trajectories complement each other for three countries that represent major differences in trajectories (See Figs. 5, 6, 7 in Appendix 1 for the remaining countries). The Czech Republic represents Group 1, also including Hungary, Poland, Slovakia and Slovenia, in which only a minimal increase in mortality rates occurred for the entire population and in which mortality declined along with fertility for the remaining years of transition. All remaining countries experienced significant increases in mortality after the transition to a market economy. Some variation among these countries exists: Bulgaria, Estonia, Latvia, Lithuania and Romania form Group 2 in which considerable increases in mortality rates occurred while fertility rates plummeted, but later recovered to pre-transition mortality levels. Russia represents Group 3, including Belarus, Moldova, Russia, Kazakhstan, Ukraine, Armenia, Georgia, Azerbaijan, Kyrgyzstan, Tajikistan, Turkmenistan and Uzbekistan all of which have either only tentatively achieved stable mortality rates or have not at all. In general, and particularly in regards to Estonia, Russia and Armenia, the point at which mortality peaked and began to decline coincides with a shift in fertility trends in which the declines markedly reduced speed; these parallel shifts point to contextual forces.

In summary, this indicator demonstrates that conditions in the FSU, Romania and Bulgaria differed enough from the CEE countries in the early 1990s that they were not able to keep mortality rates stable during the initial years of transition from communism. As mentioned, the relationship between mortality and fertility trends is not argued here to be causal; merely, the implication of mortality instability is that only the five countries of Group 1 (Czech Republic, Hungary, Poland, Slovakia, and Slovenia) could be characterized as having conditions amenable to a SDT or postmaterialist revolution in the first half of the 1990s, while conditions for those countries in Group 2 (Bulgaria, Estonia, Latvia, Lithuania and Romania) appear amenable only in the second half of the 1990s and conditions in the remaining countries (group 3) appear unsuitable for a SDT until at least 2003.

Besides a context that is in line with the theoretical tenets of SDT, we would also expect evidence of the major SDT symptom associated with fertility decline: postponement of childbearing. However, postponement may be brought on by an altogether different motivation than argued in SDT. A "postponement transition" (Kohler et al. 2002) might occur if families decide to wait to have children because of socioeconomic insecurity. Contextually, this thesis aligns with the postcommunist experience; therefore, there are no major theoretical conflicts with applying this explanation to the complete range of post-communist countries. However, this thesis clearly relates the issue of low fertility to postponement and its distortion of the period fertility measure that has defined lowest-low fertility. Therefore, the extent to which significant postponement occurred must be systematically assessed.

Kohler et al. (2002) found evidence of a PPT for countries ranging from Southern Europe to Russia, combining countries that have not experienced recent economic crises with countries that have only recently achieved economic stability; by implication, this effectively rules out the economic crisis explanation for fertility 


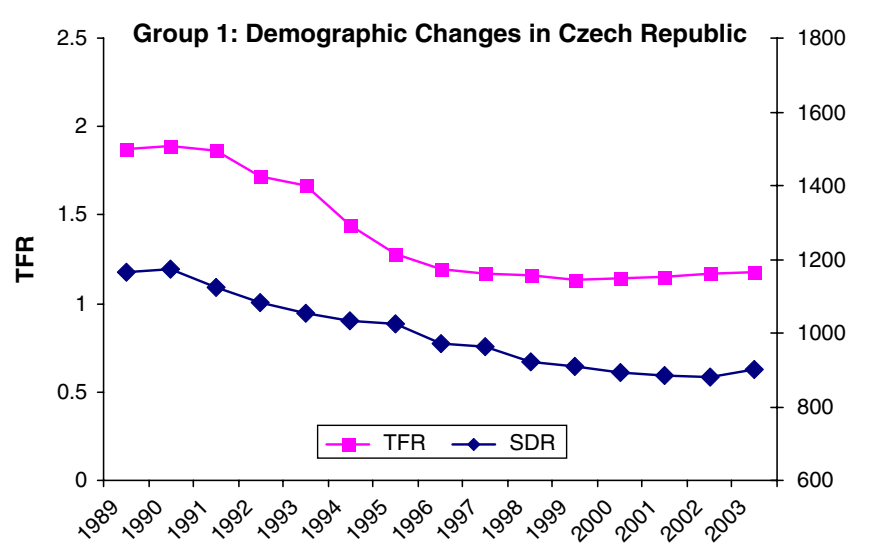

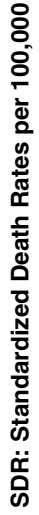

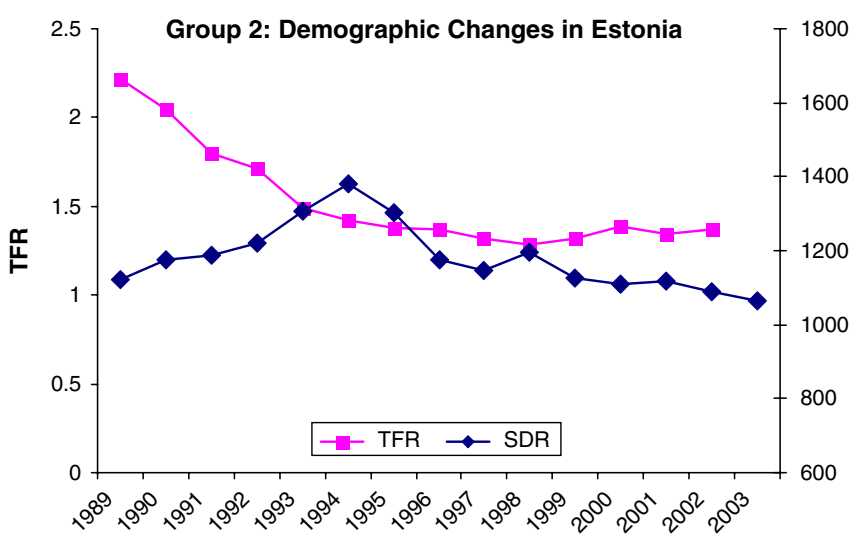

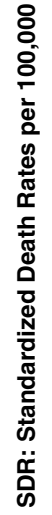
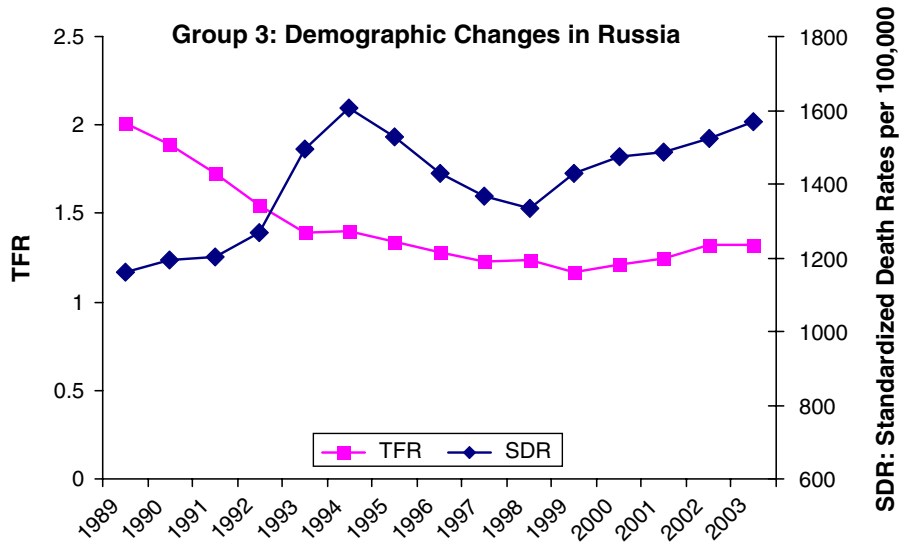

Fig. 1 Three countries representing three different patterns of fertility and mortality trajectories. Source: Author's calculations based on WHO Health for All DB and UNICEF's TransMONEE DB

decline. Not only is there great variation in the socioeconomic contexts in these authors' sample, but there is also great variation in the timing of descent into lowestlow fertility: Greece, Italy and Spain slowly declined from 1985 to 1999, losing 
between 0.2 and 0.4 TFR, while in the same time period the CEE countries lost between 0.5 and 1 TFR and the FSU countries between 0.8 to 1.4 TFR. These dramatic differences are not solely due to different starting levels of TFR and invite further research into specific aspects of the post-communist decline.

The next descriptive analyses explore to what extent postponement of childbirth is a major pattern in these countries during the first years of transition, as well as offer some indication of how important this postponement has been to achieving the depths to which fertility had fallen by the end of the 1990s. As the largest decrease in fertility occurred in the 20-24 year old population, postponement seems a likely culprit. However, the 25-29 year old age group in most countries continually mirrored the younger trend, even if to a slightly less intensity, rather than began to increase by the end of the 1990s as we would expect to see for postponement within cohorts. ${ }^{5}$ Birth rates to 30-34 year old women also stayed stable after an initial decline, rather than increasing in the late 1990s, which we would likely see if women had expected to have children at ages 25-29 and postponed until their early 30s. This is not to say that recuperation did not happen, but that birth rates still declined enough at these ages to offset the importance of any recuperation to the overall trends.

A common method of separating the impact of tempo on period fertility rates is Bongaarts and Feeny's (1998) "adjusted total fertility rate." This measure has proven a useful tool for a truer construction of what the period fertility rate is supposed to offer. However, this measure is less useful if postponement is not later matched by recuperation (Lesthaeghe and Moors 2000), as just discussed. In the present analysis, the adjusted fertility rate is not used as a measure; this is partly due to the fact that these rates have already been provided elsewhere for the countries where there is evidence of postponement over the duration of the transition. I also do not calculate the adjusted total fertility rate because the purpose here is to merely show whether significant postponement exists at all in the time period studied, the intensity of postponement and if it coincided with the initial decline in fertility rather than estimate what the TFR would be if tempo is removed from its calculation. Instead, a postponement ratio, as used by Lesthaeghe and Neidert (2006), is used to determine the degree of postponement that has taken place. However, where these authors constructed their ratio by summing age-specific fertility rates above age 30 and dividing by the sum of age-specific fertility rates for ages 20-29, the formula is altered here to reflect the post-communist context in which women have the majority of their children at a relatively young age. Therefore, the ratio used here is the sum of live births to women ages $25+$ over the number of live births to women ages 15-24.

If postponement explains the steep decline in fertility rates in the early 1990s, an increase in the birth rates of higher age groups is inevitable after a time lag. Most countries studied here at the onset of transition had an almost equal ratio (located between 0.8 and 1.2) of children born to women ages 15-24 to all women 25 years and more, demonstrating the young age structure of childbearing in these countries. The exceptions are the countries that still had a prevalence of high-parity births at

\footnotetext{
${ }^{5}$ Figures depicting the slopes of age-specific birth rates by country are excluded for reasons of space, but available upon request.
} 
the transition onset, demonstrated through a high ratio (Azerbaijan, Kyrgyzstan and Uzbekistan: 1.5, Tajikistan: 1.9, and Turkmenistan: 2.3), and Bulgaria, which had an unusually low ratio of 0.7 at the beginning of the transition. Figure 2 shows the changes in the postponement ratio from 1989 to 2003 on similar scales for better comparison. The five countries that stood out in the first descriptive analysis again are distinct from the others. More heterogeneity among the remaining countries is evident in regards to the postponement ratio; therefore, four different figures that represent the patterns appear in Fig. 2 below.

The initial distinction between group one and the remaining countries is one in which a decline in the ratio is nonexistent or negligible, whereas the others all experienced a decline in the ratio at some point. The Czech Republic, Hungary, Poland, Slovakia and Slovenia form a distinct group because all experienced significant postponement. They all began at 1 or lower and the lowest ratio by 2003 was 1.7 in Slovakia and the highest was 3.5 in Slovenia. The postponement ratios for the second group, including Bulgaria, Estonia, Latvia and Lithuania, increased to a much lesser degree than the first group after an initial decline. At transition onset, the ratios varied from 0.5 to 0.9 and by 2003 the highest ratio reached was Latvia's at 1.6, while Bulgaria only reached 1 . In fact, the Baltic states' ratios closely parallel each other's throughout the time period. But although Bulgaria began at a much lower ratio, the trajectory in terms of the magnitude of initial decline and later increase was quite similar. The third group, including Belarus, Georgia, Kazakhstan, Moldova, Romania, Russia and Ukraine, experienced much more of a decline in the initial ratios and much less of a later increase. The range in initial ratios was 0.7 (Ukraine) to 1 (Kazakhstan). All ratios decreased in the early 1990s and a few (Kazakhstan and Moldova) decreased again in the late 1990s (in 1998 and 1999, and in 2000, respectively). This was followed by a modest increase with ranges varying between 0.9 in Ukraine to 1.3 in Kazakhstan by 2003. As evident in the figure, Belarus, Georgia, Moldova, Romania and Russia mirror each other so closely in their postponement ratios that separating their trajectories is difficult. The final group consists of countries that have not experienced any notable postponement throughout the entire transition, according to the postponement ratio: Armenia, Azerbaijan, Kyrgyzstan, Turkmenistan and Uzbekistan. ${ }^{6}$ However, as mentioned earlier in regards to some of these countries, this ratio captures more than postponement if the fertility quantum is also high, since higher parity births are born at later ages and a decrease in high parity births would obscure an increase in births to older women due to postponement. Therefore, it is not as useful a tool for capturing postponement in these latter countries as in the others in which fertility hovers around replacement level.

The point at which postponement began may indicate how strongly it is related to the initial decline in TFR; therefore, the earlier the postponement the more important it should be to the decline. To determine the year of postponement onset, this paper follows the definition set by Kohler et al. (2002) in which the year of onset is the first year in a consecutive three-year increase of at least 0.3 in the average age of mother at first birth. The following figure shows the postponement

\footnotetext{
${ }^{6}$ Tajikistan is excluded due to missing information on age specific birth rates.
} 


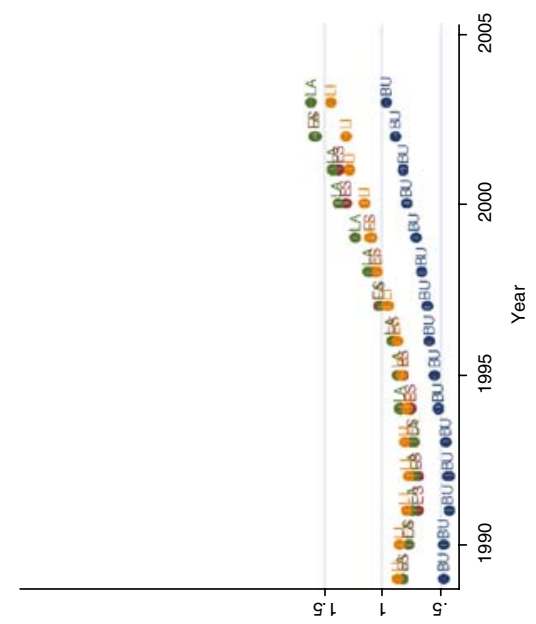

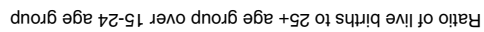

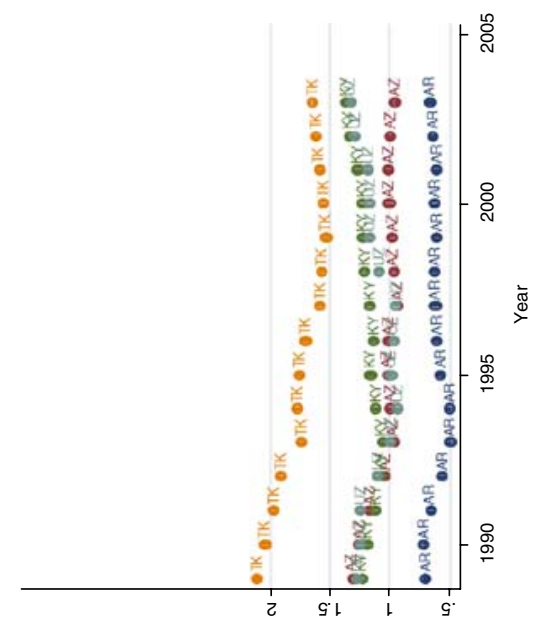

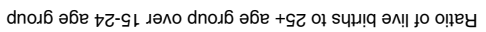

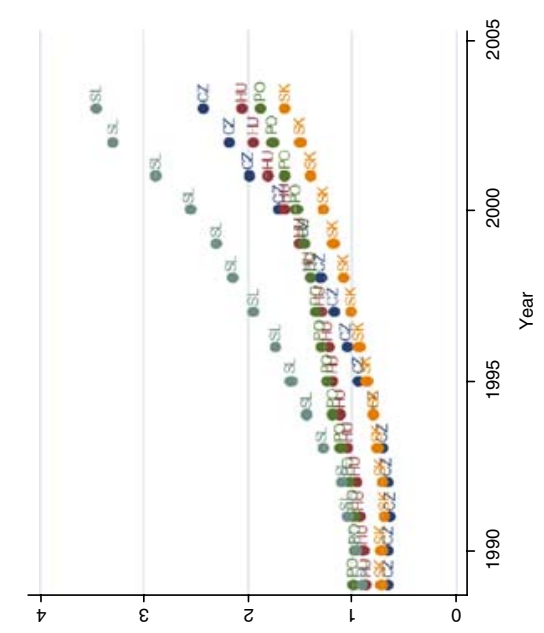

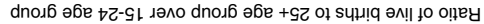

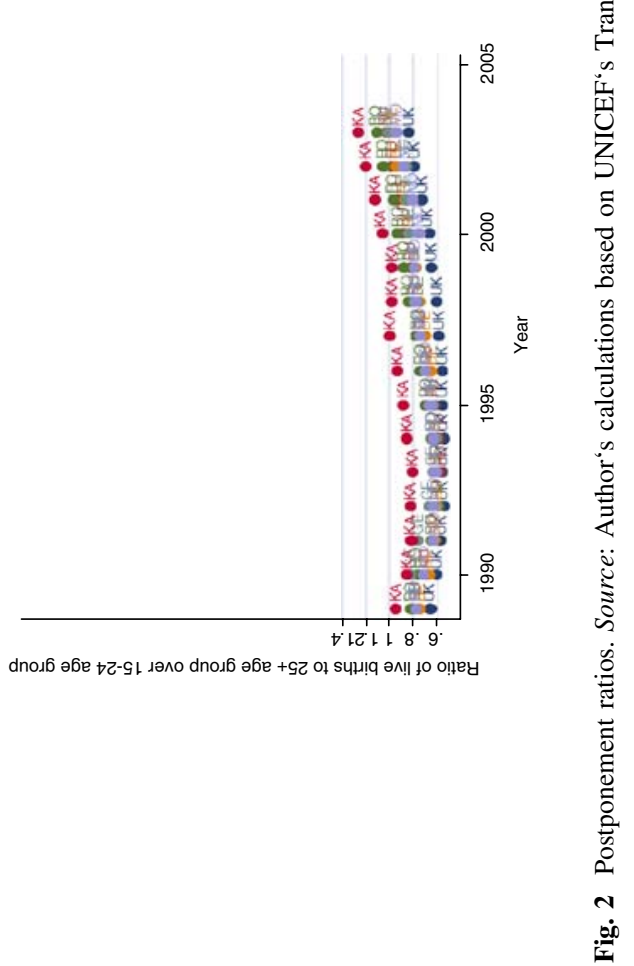


trend starting with the year of onset, plotted against the TFR to see at what point in the TFR decline postponement begins.

Group 1 countries remain distinct and are again represented by the Czech Republic in Fig. 3; their overall average onset was 1992.8. The earlier year of postponement onset is important since it further strengthens the likelihood that postponement contributed to low fertility levels, as the steepest decline in period fertility occurred during the early 1990s. Slovenia in particular may well be a case in which postponement is absolutely driving the fertility decline, as the onset of postponement began at the very beginning of the serious decline in TFR. Overall, these countries experienced between a 4 and 12\% decrease in TFR by the time postponement onset officially occurred.

All other countries that experienced postponement are represented by Russia in Fig. 3. In general, postponement began later in these countries than in Group 1 countries. Overall, these countries experienced between a 22 and $38 \%$ decrease in TFR before postponement onset occurred. Figure 3 shows that postponement preceded Russia's entrance into lowest-low fertility (below 1.3). However, more than $80 \%$ of the decline in TFR from 2 in 1989 to lowest-low levels of 1.3 preceded the onset of postponement. In fact, postponement began around the end of the TFR decline in Russia. See Figs. 8, 9 in Appendix 2 for the figures of all countries, except those in which the postponement ratios did not increase at all as a general trend.

In summary, postponement of childbirth appears to be a prominent reason the period fertility measure has declined across the Czech Republic, Hungary, Poland, Slovakia and Slovenia; whereas the extent to which postponement has played a major

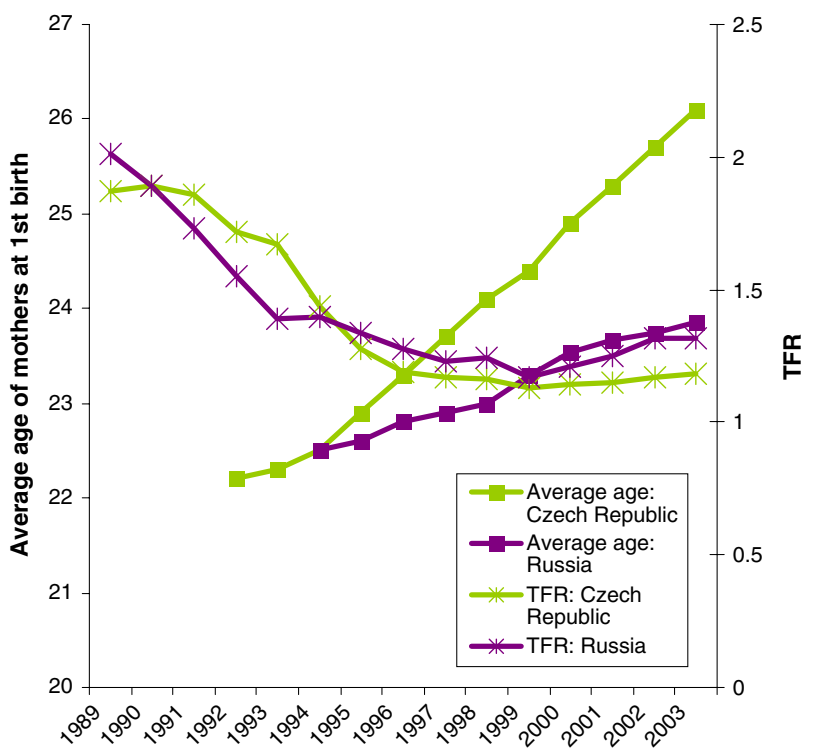

Fig. 3 Postponement onset and TFR. Source: Author's calculations based on UNICEF's TransMonee DB. Missing years for Russia (1999-2003) were substituted with Zakharov's (2008) estimations, as published in Vishnevskii (2008) 
role in the decline in TFR of the remaining countries appears limited. This finding confirms that the PPT theory cannot explain fertility decline in Armenia, Belarus, Bulgaria, Estonia, Latvia, Romania, and Russia, although postponement may still have been the final push that suppressed TFR to lowest-low fertility levels. Besides the lack of explanatory power the PPT thesis has for the majority of these lowest-low post-communist countries, the ramifications of postponement may be different in this region from those in Western Europe. With a later onset of childbearing, the quantum of fertility is known to decrease (Kohler et al. 2002; Billari and Kohler 2004). The strength of this negative association in the post-communist countries remains to be seen; there is reason to doubt the total impact given the disparity between the degrees of postponement discussed. According to Kohler et al., the average age of Southern European mothers at first birth in 1999 was 28.3 years, while the average age of mothers in post-communist countries at first birth in 1999 was 23.9. This difference of almost five years puts current mothers in the post-communist countries at the same age as mothers in Southern Europe before their PPT began. In other words, the argument that "fertility postponed is fertility foregone" may not apply when postponement occurs at a relatively young age.

Despite the simple tools used in this analysis, findings confirm those of other researchers. Using Bongaarts and Feeney's adjusted TFR (1998), Philipov and Kohler (2001) found a significant difference between the declines in Bulgaria and Russia and those in the Czech Republic, Hungary and Poland. Whereas the declines were clearly due to tempo effects in the latter cases, quantum drove the early years of decline in Bulgaria and Russia. Sobotka $(2002,2003)$ found a wide variation in the contribution of tempo to declining period fertility rates as well. These authors also attribute these findings to the more severe economic reaction to transition in these two cases.

To summarize this descriptive exploration, three discrete country groups emerge in this region. Due to escalating mortality rates, only five countries display conditions amenable to a SDT throughout the entire transition: Czech Republic, Hungary, Poland, Slovakia and Slovenia. These same five countries also exhibit signs of significant postponement of first birth as well as fertility declines that coincide with the increase in age at first birth. Therefore, for five of the post-communist countries discussed here, either SDT or a PPT may be the force behind their entire fertility decline; as stated earlier, this analysis does not attempt to distinguish between SDT and PPT in the cases where either might fit. Research using disaggregated data may be more able to distinguish the mechanism behind postponement.

Figure 4 summarizes the following findings. While postponement appears to be the process behind fertility decline during most of the transition in those five countries of Group 1, it appears to be the process behind fertility decline in only the later half of the 1990s in the four countries of Group 2: Bulgaria, Estonia, Latvia and Lithuania. ${ }^{7}$ These four countries appear to be a mixed-process group in which economic crisis explanation appears to be at work in the turbulent early 1990s because postponement was minor and conditions were not amenable to an SDT.

\footnotetext{
${ }^{7}$ Romania also experienced significant postponement and recovery of mortality rates, but the ratio of age-specific births to older women over age-specific births to younger women indicates a scenario much closer to the third group of countries.
} 


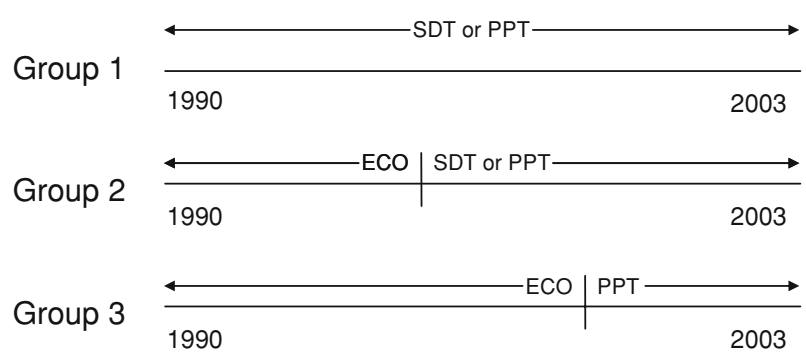

Fig. 4 Summary of descriptive findings. Note: Group 1 includes Czech Republic, Hungary, Poland, Slovakia and Slovenia; Group 2 includes Bulgaria, Estonia, Latvia and Lithuania; Group 3 includes all remaining former Soviet Union countries and Romania. SDT Second demographic transition, PPT postponement transition and $E C O$ economic crisis explanation

However, after the mid-1990s, economic recovery, mortality stability and the presence of substantial postponement leave room for either a SDT or PPT explanation. Group 3 includes countries that did experience postponement by the end of the 1990s, but because mortality rates have still not recovered, conditions appear unlikely for SDT to be a major explanatory force for declining fertility, leaving PPT as a likely explanation for only recent low levels of fertility. In summary, two processes seem to be at work-postponement of childbearing and stopping behavior-and one of these two processes characterizes the majority of the fertility decline for two groups of countries (Groups 1 and 3), while both processes are almost equally present in the mixed-process group (Group 2).

Including more countries and later years, this analysis confirms the general findings of Sobotka (2004): although TFR was negatively affected to some degree by the postponement of childbirth, regional differences in period fertility still existed even after taking postponement into account and, thus, there were at least two pathways of fertility change for the post-communist countries. Moreover, the data that is available shows what we would expect according to theory and past research: the countries showing the most striking increase in higher education enrollment rates (Group 1 countries) are the ones that also demonstrate evidence of significant postponement, rather than stopping behavior.

\section{Regression Analyses}

This section contributes to the study of fertility decline in the post-communist region by analyzing whether: (1) the variation in fertility behavior can be statistically linked to two different processes: stopping behavior and postponement of first birth; and (2) whether these different processes are conversely related to economic context. Specifically, the hypotheses are as follows:

H1 The fertility declines of Group 3 were distinct from those of Group 1 and were driven by economic crisis.

Hence, if stopping behavior drove the decreases in fertility in Group 3, then a reduction in age specific birth rates, especially at older ages, should be evident for 
those countries. Moreover, if the economic crisis drove these declines in birth rates, then the difference between the groups of countries should disappear if we account for economic context.

H2 Postponement of childbearing drove the fertility decline of Group 1 and a more positive economic environment encouraged this delay in childbearing.

Hence, the likelihood of experiencing postponement onset, as defined in the previous section, will be lower for countries of Group 3 than Group 1. Moreover, if a positive economic context is related to the likelihood of postponement onset, the difference between the two groups should be rendered statistically insignificant with the inclusion of variables that capture the economic context.

Due to the presence of Group 2 countries, which clearly exhibited both processes in the descriptive analyses, a static two-group categorization may not be appropriate. Ideally, these mixed-process countries would be able to contribute to both groups according to which process was underway by year. Unfortunately, complications arise with this strategy ${ }^{8}$; instead, the strategy adopted is to run the models twice, putting these mixed-process countries first in Group 1, then 3. If these countries truly experienced both processes, and variation in the economic context explains these processes, then the placement in either group should work almost equally well. Results confirm this assumption and although I present findings of only one classification for simplicity, the models for the additional group specifications can be found in Tables 5 and 6 in Appendix 3 and Table 7 in Appendix 4.

\section{Data and Sample}

To test these hypotheses, I use cross-sectional time-series data mostly taken from the TransMONEE database. This database "contains data related to the social and economic situation and wellbeing of children, young people and women in CEE, the CIS and the Baltic States (CEE/CIS)." It is associated with the MONEE Project: Public Policies and Social Conditions: Monitoring the Transition in CEE and the CIS and was initiated by UNICEF Innocenti Research Centre in 1992. The database consists of annual data received from the National Statistical Offices of each country and uses a standardized template. I include as many post-communist states as the data allow, excluding most Central Asian Republics (CAR), for the 13 year period of 1990-2003. The sample includes Armenia, Azerbaijan, Bulgaria, Czech Republic, Estonia, Georgia, Hungary, Kazakhstan, Lithuania, Poland,

\footnotetext{
${ }^{8}$ The countries were selected into the groups according to multiple pieces of evidence, which increases the difficulty of selecting one variable that would indicate a single year when a country transitioned from crisis as a driving force of fertility decline to economic stability and postponement. When analyzing age specific birth rates, it was possible to take the year of postponement onset or beginning of mortality recovery, whichever happened first, as the year in which these countries moved from Group 3 to 1 . While neither of these bases is directly endogenous to the age specific birth rate models, this basis is problematic for determining the groups for the postponement models. Due to the lack of one clearly exogenous variable to establish a single point in time, I did not attempt this strategy for the postponement models. It is worth noting that the results presented in the following selection are robust to the group categorization in which the mixed-process countries change groups over the time series in this analysis. See Tables 5 and 6 in Appendix 3.
} 
Moldova, Romania, Russia, Slovakia, and Ukraine. Not included are the Southeastern European countries of Albania and the former Yugoslavia as well as Belarus and Latvia, due to complete lack of data for one or more variables, and the former East Germany (GDR). ${ }^{9}$ Although the CARs were included in the descriptive analyses, they are not included here due to the confounding influence of the decline in higher order births that would accompany a First Demographic Transition. ${ }^{10}$ Kazakhstan remained in the analysis as the TFR was already well below 3 before the transition from communism began. Although this sample does include a few countries that experienced conflict within their borders (Azerbaijan, Georgia, and Moldova) during the early years of transition, the results proved to be robust when excluding these countries. In summary, the analysis includes 15 countries for 14 years $^{11}$ and the range in TFR at 1990 was 1.81 (Bulgaria) to 2.77 (Azerbaijan).

\section{Measures}

Five different dependent variables (DVs) are used: age-standardized live birth rates (live births per 1,000 women) for 15-19, 20-24, 25-29, 30-34 and 35+ year old women. The majority of variables show greater within variance than between. ${ }^{12}$ All independent variables have been lagged by 1 year. Originally, a 2 year lag was considered more likely, due to a 9 month gestation period; however, tests consistently showed the relationship to be stronger with a 1 year lag.

Fertility rates are subject to non-stationarity; for this reason, I took the first differences of all my DVs. This solution is a viable approach as my theoretical interest is in the changes in fertility rates caused by the explanatory variables and not the absolute levels. Maddala's (Maddala and Wu 1999) Fisher test for panel unit root using the augmented Dickey-Fuller test rejected the possibility of a unit root for all my DVs once they were transformed into first differences. The theta score in a random effects regression and the Breusch and Pagan Lagrangian multiplier test for random effects revealed the adequacy of a pooled model to represent the variance in this data. Before taking the first differences of my DVs, a fixed effects estimator proved to be the best fit, but transforming the DVs into changes in rates rather than actual rates removed country specific effects. Moreover, the inclusion of a control variable for the initial TFR also removes substantial fixed effects. Durbin's $\mathrm{M}$-test and the Baltagi and Li test for serial correlation in panel data indicated that

\footnotetext{
9 The former GDR is not included in the Trans MONEE database, and therefore the comparable standardized indicators used in the analysis are not readily accessible. The former GDR would be an interesting inclusion to this sample due to the remarkable drop in TFR during the early years of transition ( 1.5 in 1990 to 0.8 in the years 1992-1995), but the contextual differences brought about by its absorption into a wealthy country and national culture characterize its transition with specific and unusual conditions in comparison to all other post-communist cases.

${ }^{10}$ Nevertheless, previous models that include Kygyz Republic, Tajikistan and Uzbekistan demonstrate that the results are robust whether they are included or not.

11 There are a few years in which data is missing for a few countries within this time period.

12 Correlation charts and summary statistics are omitted for reasons of space and are available upon request.
} 
taking first differences removed autocorrelation from this data. To deal with heteroskedasticity, I estimated the model by using the Linearization/Huber/White/ sandwich robust estimates of variance. ${ }^{13}$

"Economic crisis" is represented with four variables: GDP, inflation, employment ratio and wage growth. The indicator used for inflation is the $(\log )$ "annual percent change in consumer prices" (IMF World Economic Outlook 2000, 2003). The measure for GDP is per capita and expressed in purchasing power parity (PPP). Because the interest here is not in the absolute wealth of a country, but rather the changes from year to year, or more specifically the decline in GDP, this indicator is the difference in GDP from 1 year to the next. This means that the starting year of the time series-1990-reflects the difference between GDP in 1990 and 1989.

Rather than focus on unemployment rates, which offer a rate based on the total labor force, employment rates are used to better capture the influence of how many individuals are working in relation to the total working age population, not just those technically in the labor force. This measure should be more sensitive to assessing women's status since they move in and out of the labor force more often than men for family reasons or may be more likely to not participate in the labor force due to family reasons when the economy is performing poorly. But it also ensures we are capturing shifts in employment levels that would also affect spouses and, hence, are reflecting conditions at the household and not just individual level. Specifically, the measure used in this analysis is an employment ratio: the number of employed as a percent of population aged 15-59.

Real average wage growth is "a proxy for the quantity of goods and services a money wage can buy; the real wage represents the money wage adjusted for inflation. ${ }^{14}$ Values are an index based on the value of 100 at the base year" (TransMONEE 2007) and, therefore, reflect cumulative changes in wages since the onset of transition and not year-to-year wage growth.

The key indicator is "group," which separates the countries according to the division that emerged in the descriptive analysis. As mentioned, the intermediate group of countries, or the mixed-process group (Bulgaria, Estonia, Latvia and Lithuania), are dealt with by: (1) placing them in analyses with Group 1 countries (Czech Republic, Hungary, Poland, Slovakia and Slovenia), where a more stable economic environment is argued to be driving postponement, (2) placing them with Group 3 countries (Armenia, Azerbaijan, Belarus, Georgia, Kazakhstan, Moldova, Romania, Russia and Ukraine), where economic crisis is argued to have contributed to stopping behavior. The results that are displayed are those for the best model, but results for the alternative country groupings can be viewed in Tables 5 and 6 in Appendix 3 and Table 7 in Appendix 4.

Finally, I include one control variable: initial TFR. Including the fertility rate at the starting point of the fertility decline - according to the years analyzed heremay capture any country-specific effects such as the impact of culture on overall

\footnotetext{
${ }_{13}$ I also attempted models based on nonlinear specifications, but without better results.

14 "IRC estimate. Consumer price index taken from EBRD (2003) Transition Report Update, 2003. London: European Bank for Reconstruction and Development; 2002-2003 are preliminary data." (Trans MONEE 2004).
} 
fertility behavior. Moreover, it may also account for specific characteristics of fertility behavior at certain levels of TFR that might confound the analysis.

The model is designed to be sparse; only those aspects that will confirm whether economic conditions explain changes in fertility rates are introduced into the model. Therefore, the regression analyses are not testing the explanatory power of alternative hypotheses. Other research has included explanatory variables in the models such as the marriage rate, age of first birth, and divorce rate (e.g., Cornia and Paniccià 1998; UN ECE 2000). These are important determinants of fertility and have themselves been the foci of much research. However, as these factors themselves may be impacted by deteriorating economic conditions, they would likely introduce endogeneity into the model. Therefore, I do not include them as explanatory or control variables.

In this analysis, the benefits of having time-series data that include pre-transition years are sacrificed in order to have data that covers most of the countries that were part of the Eastern Bloc. In identifying causality, the "no cause-no effect" condition (Bhrolcháin and Dyson 2007) is best satisfied by observing a single or a few cases over long periods of time, but here it has been satisfied by observing the degree of effects based on the degree of changes across many countries over a shorter period of time, which adequately meet counterfactual criteria (Esping-Andersen and Przeworski 2000). As such, the conclusions found here are more relevant to the speed and intensity of fertility decline than to the occurrence of decline, since all countries experienced a decline to some degree.

To formally test the claim that there are significant differences between the country groups that emerged according to the process behind the fertility decline, as well as a mixed-process group, step-wise regressions are used. First, bivariate regression analysis with a dummy variable separating the groups will tell us if there is a significant and meaningful difference between the two when regressing the fertility measure on the groups. The descriptive evidence suggests that declines in the fertility rates of countries of the third group will be more intense. Hence, in Model 1 being a country of Group 3 will have a negative impact, in reference to Group 1, on changes in fertility. Second, adding the economic indicators to this model will indicate if economic context variables explain the differences between the country groups. If the continued worsening of the economic situation was an important condition under which the fertility decline was more intense or consistent, the effect of the Group dummy should disappear. Hence, in Model 2, worsening economic conditions should negatively impact fertility, while rendering the Group dummy no longer significant. ${ }^{15}$ In other words, the first model will confirm the overall difference between groups and show in what direction the difference is, whereas the second model will show that the difference becomes negligible or reversed if we take into account the economic context. The value of the second model

\footnotetext{
15 One important concern over using such interrelated economic variables (GDP, inflation, employment ratio and wage growth) is the extent to which multicollinearity biases my results. Indeed, the dummy separating the two groups of countries had a correlation score of .69 with GDP. Transforming GDP into the difference in GDP greatly relieved the collinearity between these variables. In any case, the variance inflation factor (VIF) score reads 1.67, which is below the danger realm of 2.0-10 VIF score (Cohen et al. 2003) and assures that the results are not biased by multicollinearity.
} 
is in seeing the change in the group dummy coefficient/odds ratio between the two models when we include the economic indicators. Therefore, the final model is:

$$
\begin{aligned}
\Delta \text { Fertility }_{i t}= & \beta_{0}+\beta_{1} \text { type }_{i t-1}+\beta_{2} \text { wagegrowth }_{i t-1}+\beta_{3} \text { empgrowth }_{i t-1} \\
& +\beta_{4} \text { inflation }_{i t-1}+\beta_{5} \Delta \text { GDP }_{i t-1}+u_{i t}
\end{aligned}
$$

Where $\Delta$ indicates the change in the age specific birthrate for country $i$ at time $t$. $\beta$ s are the coefficients of the explanatory variables at $t-1$ and $u$ is the error term.

Finally, to further confirm the distinct processes behind the fertility declines of the two groups-and whether economic context is also related, but conversely, to postponement - a logistic regression analyzes whether the group dummy captures the difference in likelihood of postponement. The DV in these regressions is dichotomous, in which 0 indicates there was no increase in the average age of mother at first birth and 1 indicates an increase. To conform to the idea of postponement as a transition, the increase is considered to exist only if it is past the point of postponement onset, as defined above, to exclude the minute fluctuations both up and down in mothers' average age at first birth. The second model in the logistic regression includes the same economic variables as discussed above to test whether the same forces behind the declines in fertility are behind the increase in mothers' ages at first birth when postponement had begun. Step-wise inclusion of the economic indicators is used here as well, following the strategy outlined above. It is expected that in Model 1, being a country of Group 3 will reduce the likelihood of postponement; while the addition of the economic variables will render the type dummy insignificant in Model 2 and improvements in the economic indicators will increase the likelihood of postponement.

\section{Results}

Table 3 displays results for the linear regression models of age-specific birth rates. Model 1 regresses the age-specific birth rates on the group dummy only. In general, the hypothesis related to Model 1 holds: Except for the two youngest age groups, the coefficient for belonging to Group 2 is negative, meaning that the decline in births at higher ages is greater for countries in Group 2. This coefficient is statistically significant in the country grouping for births to 30-34 and 35+ year old women in this country grouping. It is also statistically significant for the 25-29 year olds when the mixed-process countries are included in Group 3, rather than Group 1, as well as when their contribution to the groups varies by year (See Tables 5 and 6 in Appendix 3). In the case of teen birth rates and the 20-24 year olds, the coefficient for the group dummy was consistently positive and insignificant. A positive relationship makes sense for women of younger ages in Group 3 countries; postponement is most likely to suppress age-specific birth rates at younger ages and we expect to see greater postponement in Group 1. However, these coefficients are not statistically significant at the younger ages and, in the case of 15-19 year olds, it is particularly low.

Model 2 also displays results in line with the hypothesis: the difference in the intensity of decline in fertility between Group 1 and Group 3 is mediated by the economic context and especially so at older ages. The impact of the country group 


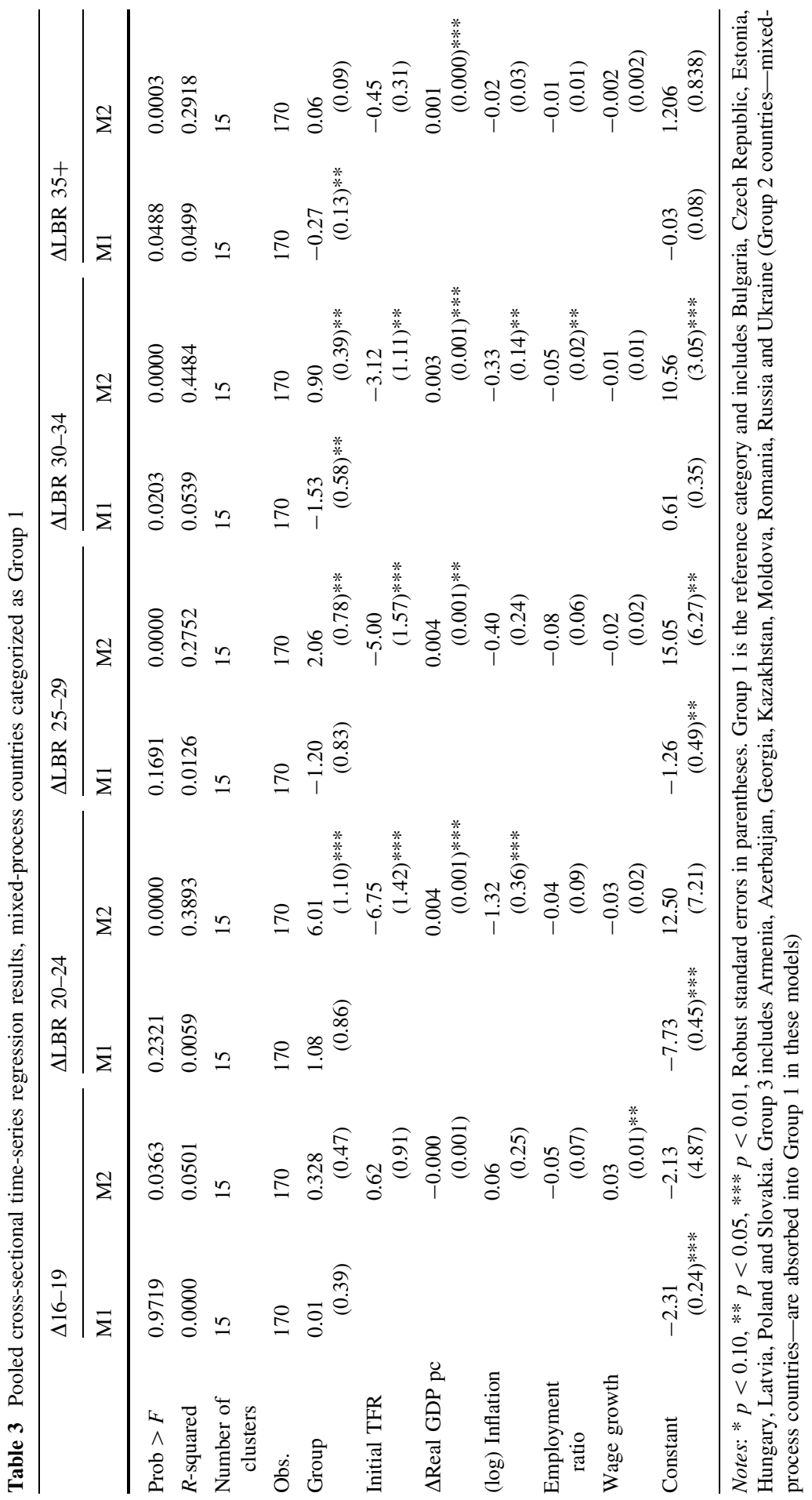


dummy disappeared or completely reversed when the economic variables were introduced into the model. The exception again is the younger age groups (teens and the 20-24 year old women), in which the coefficients for belonging in Group 3 have the same direction when the economic context variables are included as when they are not included, although their size increases.

In regards to the specific impact of these economic indicators, the results are complex. Only in the case of live births to teens did wage growth prove to be important. This finding was consistent across the two parallel analyses that distribute the countries among the groupings differently (See Tables 5 and 6 in Appendix 3). In Model 2, inflation consistently has the expected relationship (negative) with birth rates of all women 20 and above, but it is significant only for the 20-24 and 30-34 age groups. The employment ratio also had a negative relationship with fertility, which contradicts the crisis-related expectation that when employment increases fertility should increase. Rather, the relationship is what we would expect to see according to traditional economic theory: increased employment-assuming this translates into increased employment for women as welldecreases fertility due to the indirect costs associated with childbearing. However, it is only statistically significant for the 30-34 year old women. GDP per capita was significant and had the expected relationship with all fertility outcomes except the 15-19 age group. As the economy improved in general, changes in fertility were positive as well. The control variable, initial TFR, was significant for women between the ages of 20 and 34 in which the coefficient was negative but its impact diminished at higher ages.

Overall, these results demonstrate that not only does the economic context absorb important variation in the underlying processes of fertility decline of the country groups, but that worsening economic conditions were related in general to the decreasing fertility rates. Where this was not the case was for the age group that would be most impacted by postponement, rather than stopping behavior.

Logistic regressions on the likelihood of postponing childbirth are displayed in Table 4. ${ }^{16}$ As expected, Model 1 indicates that countries of Group 3 had a lower odds ratio of experiencing a significant increase in the average age of mother at first birth than countries of Group 1 during this time frame, demonstrating once again that different processes occurred in these two groups during the fertility decline. This difference reversed entirely once economic indicators were included in the model; the odds ratio became positive, although statistically insignificant. In the final model, change in GDP per capita was significant, where increases in GDP improved the likelihood that postponement would occur. Although the employment ratio and inflation did not have the expected impact on postponement, the odds ratios are not statistically significant, whereas the direction of wage growth is as we would expect. Finally, this general story holds true for the alternative grouping of countries, which is displayed in Table 7 in Appendix 4.

\footnotetext{
16 The comparison of the results for the two different country groupings reveals that including the mixedprocess countries with Group 1 does not achieve a statistically significant model at any level; therefore, the results for the model in which the mixed-process countries are placed in Group 2 are displayed. However, the direction of all odds ratios is the same in the two groupings, as well as the significance of all other indicators in Model 2.
} 
Table 4 Logistic regression results for postponement of childbirth, mixed-process countries categorized as Group 3

\begin{tabular}{lll}
\hline & \multicolumn{2}{l}{ Logistic regression postponement } \\
\cline { 2 - 3 } \cline { 3 - 3 } & M1 & M2 \\
\hline Prob $>\chi^{2}$ & 0.0052 & 0.0000 \\
Pseudo $R$-squared & 0.0670 & 0.4515 \\
Log pseudo likelihood & -89.660 & -52.707 \\
Obs. & 147 & 147 \\
Group & $0.22(0.12)^{* * *}$ & $1.82(1.93)$ \\
Initial TFR & & $0.13(0.20)$ \\
$\Delta$ Real GDP pc & & $1.004(0.001) * * *$ \\
(log) Inflation & & $0.84(0.13)$ \\
Employment ratio & & $0.99(0.07)$ \\
Wage growth & & $1.02(0.02)$ \\
\hline
\end{tabular}

Notes: $* p<0.10, * * p<0.05$, *** $p<0.01$, Robust standard errors in parentheses. Group 1 is the reference category and includes Czech Republic, Hungary, Poland and Slovakia. Group 3 includes Armenia, Azerbaijan, Bulgaria, Estonia, Georgia, Kazakhstan, Latvia, Moldova, Romania, Russia and Ukraine (Group 2 countries-mixed-process countries-are absorbed into Group 3 in these models)

In summary, these two sets of regression analyses establish a clear distinction between two groups of post-communist countries that appeared distinct in the descriptive analyses. Those in Group 1 demonstrated postponement behavior, whereas those in Group 2 demonstrated stopping behavior. The fact that the mixedprocess countries perform almost equally as well in either group, with the results telling the same story, further reinforces the hypothesis that two processes underlie the country group distinction. Moreover, the changes in the group dummy coefficient between Model 1 and Model 2 systematically show that the relationship between the country grouping and the fertility measure is mediated by the economic context. In other words, from 1990 to 2003, postponement was linked to improvements in the economic context, whereas stopping behavior was related to worsening economic conditions.

\section{Discussion and Conclusions}

The first purpose of this paper was to establish that there were indeed different processes behind declines in post-communist fertility rates. Three groups emerged across this region. The first group appeared to have undergone a PPT or SDT early on in the transition from communism (Czech Republic, Hungary, Poland, Slovakia and Slovenia). The second group appears to have undergone a PPT or SDT later in the transition from communism. They experienced fertility decline before major postponement of childbirth (Bulgaria, Estonia, Latvia and Lithuania). The third group appears to have experienced postponement of childbirth, if at all, only much later in the transition from communism and after extensive fertility decline had already occurred (Armenia, Azerbaijan, Belarus, Georgia, Kazakhstan, Moldova, Romania, Russia and Ukraine). The countries and time periods that do not display 
strong postponement appear to have undergone a more traumatic transition in which major health crises ensued and fertility declines were more intense. These distinct findings, regarding the divergence among countries, confirm Sobotka's (2002) findings as well as specific research on individual countries (e.g., Sobotka et al. 2003 on the Czech Republic; Perelli-Harris 2005 on Ukraine).

The second purpose of this study was to empirically test whether this profound drop in fertility rates indicates a reaction to problematic transitions, or economic crisis. The results reaffirm research that has found a link between depressed economic conditions and declining fertility for the countries where postponement of childbirth did not appear to play a major role in the initial decline in fertility rates. Conversely, when the economic context was more stable, postponement was more likely to take place. The results contribute to the empirical verification that the economic crisis, or its absence, mattered to the manner and intensity of fertility decline.

The framing of this study-looking beyond static country groups-accommodates the dynamic reality that the economy decreases in importance to fertility decisions according to its performance. Therefore, finding evidence of countries moving between the two groups according to changes in the economic context offers more support for the proposed mechanisms behind fertility decline than would a static grouping of countries, since it renders the country grouping mechanism less likely to be spurious.

The limitations of this study are many. First, the small sample size may have decreased the statistical significance of the models. Second, the approach and modeling of this analysis are not able to accommodate long-term factors that may be important to fertility decline. Therefore, the findings are generalizable only to the relationship between fertility and the economic context as it varies from 1 year to the next and, specifically, between 1990 and 2003. Finally, data on trends in parity births for this range of countries and years is not yet available. As this data becomes available in the future, further analyses can conclusively determine the exact processes underlying the fertility declines.

Beyond understanding the post-communist fertility decline and whether it was partially due to the economic crisis, the findings of this paper have implications for SDT and PPT theories. First, the findings offer support for the theoretical tenets of SDT theory. When the economic conditions allow for material needs to be met, postponement of childbirth does appear more likely to occur. Because the results support a relationship between positive economic performance and postponement, PPT theory does not seem as robust in this context. However, given the overwhelming social upheaval even in countries that did not experience lengthy economic crises, the uncertainty proposed in Kohler et al.'s (2002) research may also be a likely motivation for postponement of childbearing.

Further exploration on establishing the different motivations according to these two theories is needed to push the debate further. For instance, the empirical conditions for a PPT could be more clearly differentiated from those in which a SDT is likely. Another area of PPT theoretical refinement could be how increased tertiary education enrollment impacts fertility differently in a PPT context than in a SDT context. PPT theorists could also enhance their theoretical claim by addressing the role of unemployment more clearly. Some results in this analysis seem to indicate that family formation was either a 
coping mechanism for women when employment levels dropped or that there were restrictions to continuing previous family formation patterns for those women who managed to maintain employment. These issues and, in general, the question related to postponement behavior and its underlying causal mechanism-economic uncertainty (PPT) versus SDT - is best analyzed with micro-data.

A policy implication of these results is that lowest-low fertility levels in this region are not necessarily there to stay. We have already seen this as countries have begun to climb out of lowest-low fertility already: as of 2006, only Belarus, Moldova, Poland and Slovakia have TFRs that remain below 1.3. In summary, although period fertility has remained low for many years, there are indications that with better economic conditions, families may increase their willingness to have more children. At least this may be true for those countries of the post-communist region in which low fertility appears to be related to economic conditions.

Acknowledgments Many thanks to Pau Baizan, Francesco Billari, Gosta Esping-Andersen, Alexandra Pittman, and Javier Polavieja for their helpful comments on earlier drafts of this paper, as well as from Pompeu Fabra University's Demosoc Working Group. All errors are my own. I would also like to thank the anonymous reviewers for their helpful suggestions. Financial support for this study came from Generalitat de Catalunya's Agència de Gestió d'Ajuts Universitaris i de Recerca.

Open Access This article is distributed under the terms of the Creative Commons Attribution Noncommercial License which permits any noncommercial use, distribution, and reproduction in any medium, provided the original author(s) and source are credited.

\section{Appendix 1}

See Figs. 5, 6, 7.
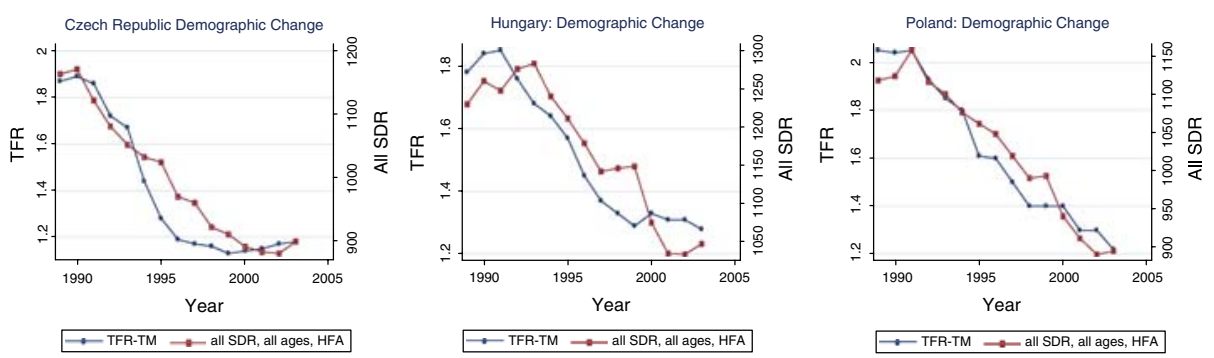

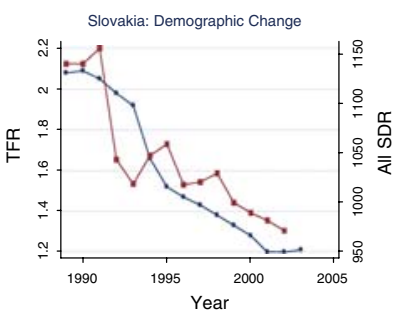

$\because-$ TFR-TM $\rightarrow$ all SDR, all ages, HFA

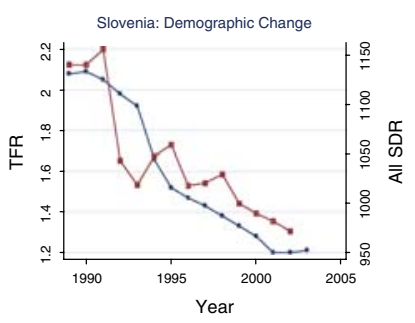

$\because-$ TFR-TM $\rightarrow$ all SDR, all ages, HFA

Fig. 5 Group 1 countries 
yOS $॥ \forall$

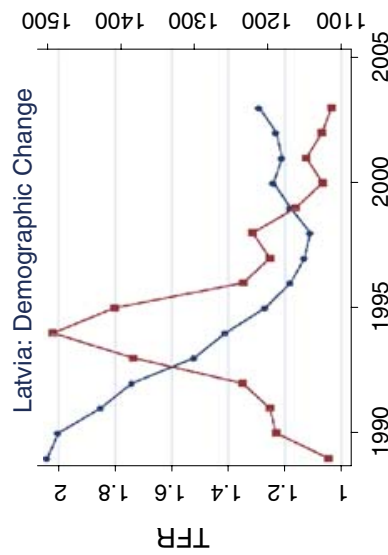

yas ॥

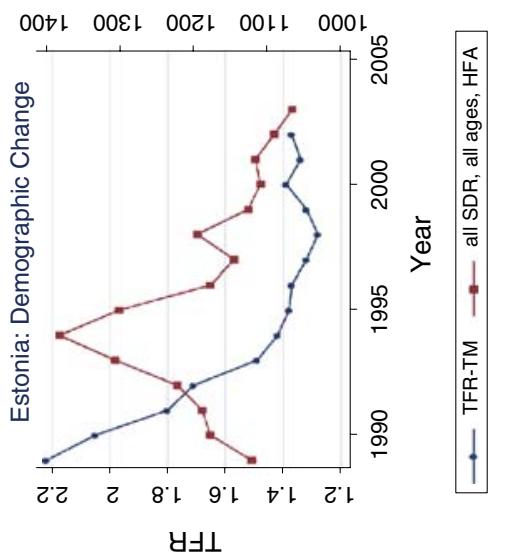

비

yas II

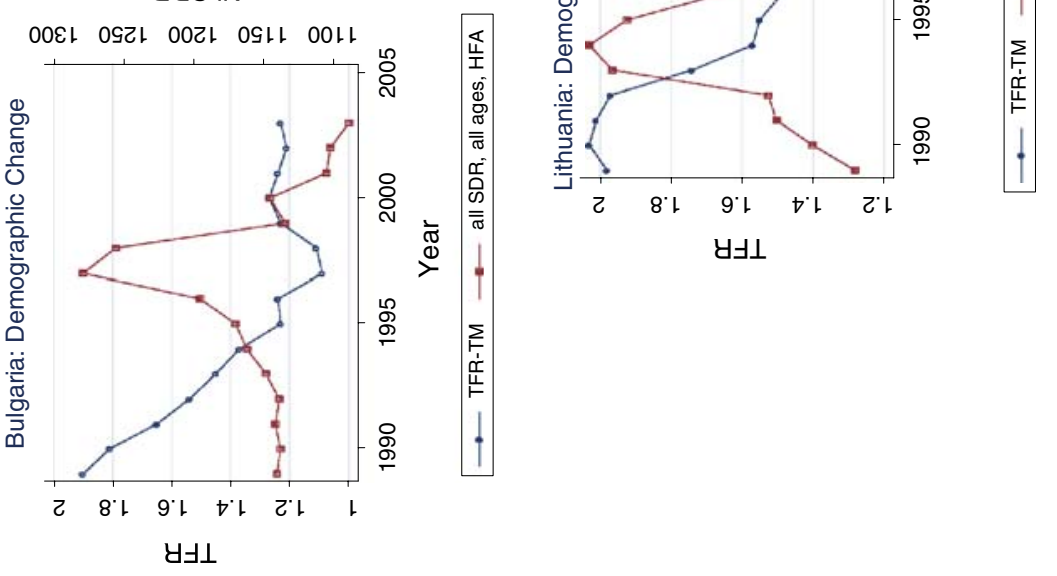

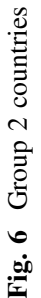




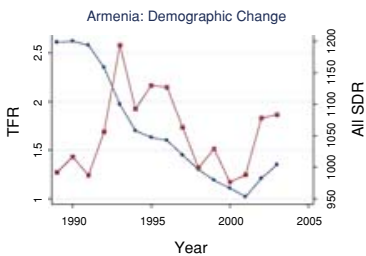

$\longrightarrow$ TFR-TM $\rightarrow$ all SDR, all ages, HFA

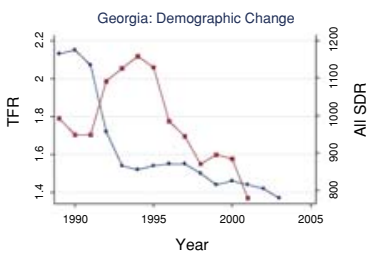

—TFR-TM - all SDR, all ages, HFA

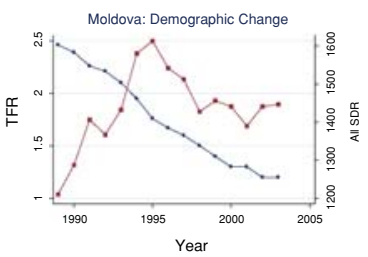

- TFR-TM - all SDR, all ages, HFA

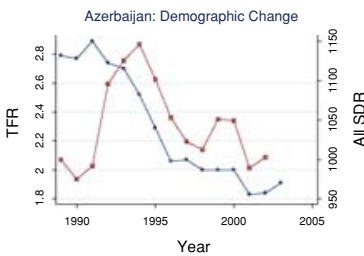

$\longrightarrow$ TFR-TM $\longrightarrow$ all SDR, all ages, HFA

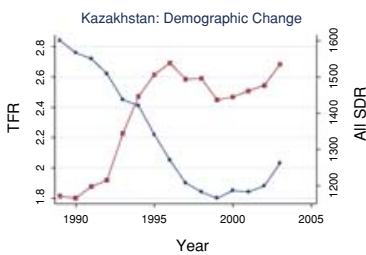

$\div$ TFR-TM $\longrightarrow$ all SDR, all ages, HFA

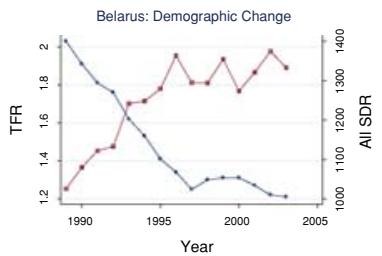

—TFR-TM - all SDR, all ages, HFA

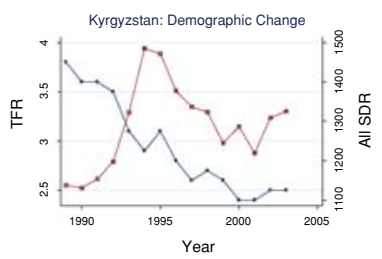

$\because$ TFR-TM $\rightarrow$ all SDR, all ages, HFA

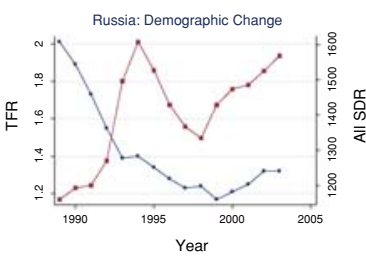

$\because$ TFR-TM $\longrightarrow$ all SDR, all ages, HFA

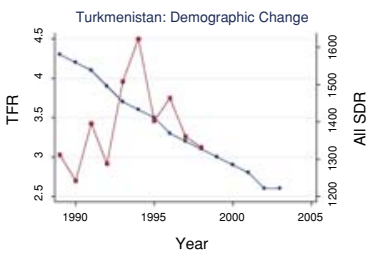

$\longrightarrow$ TFR-TM $\rightarrow$ all SDR, all ages, HFA

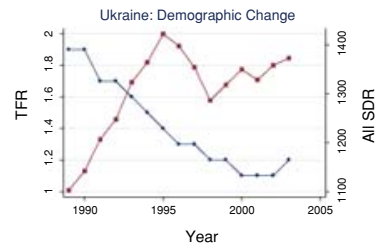

$\longrightarrow$ TFR-TM $\rightarrow$ all SDR, all ages, HFA

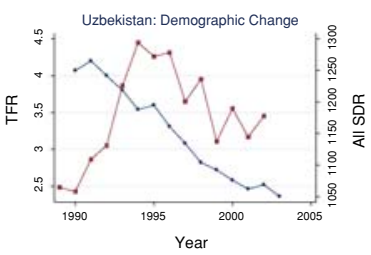

$\longrightarrow$ TFR-TM $\rightarrow$ all SDR, all ages, HFA

Fig. 7 Group 3 countries

\section{Appendix 2}

See Figs. 8, 9.

\section{Appendix 3}

See Tables 5, 6 .

\section{Appendix 4}

See Table 7. 


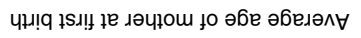

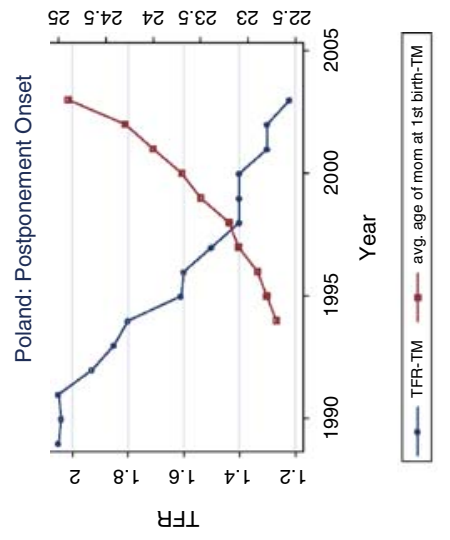

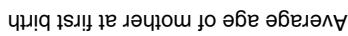

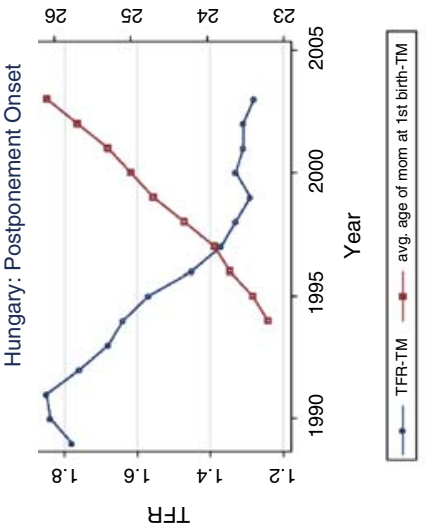

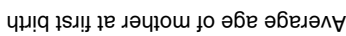

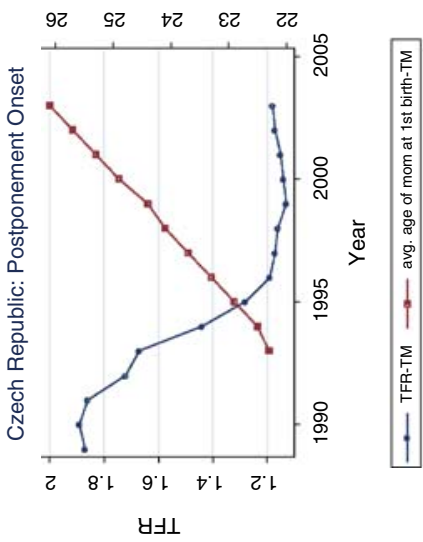

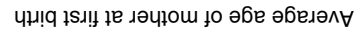

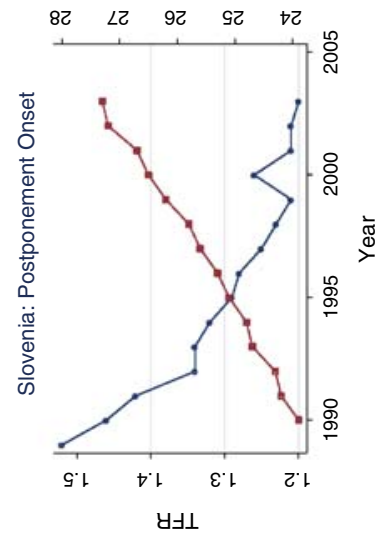

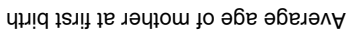

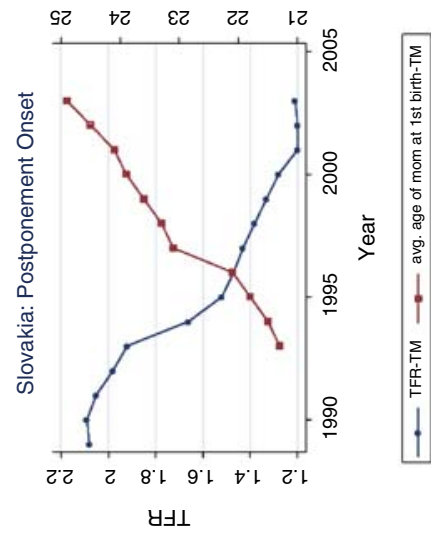



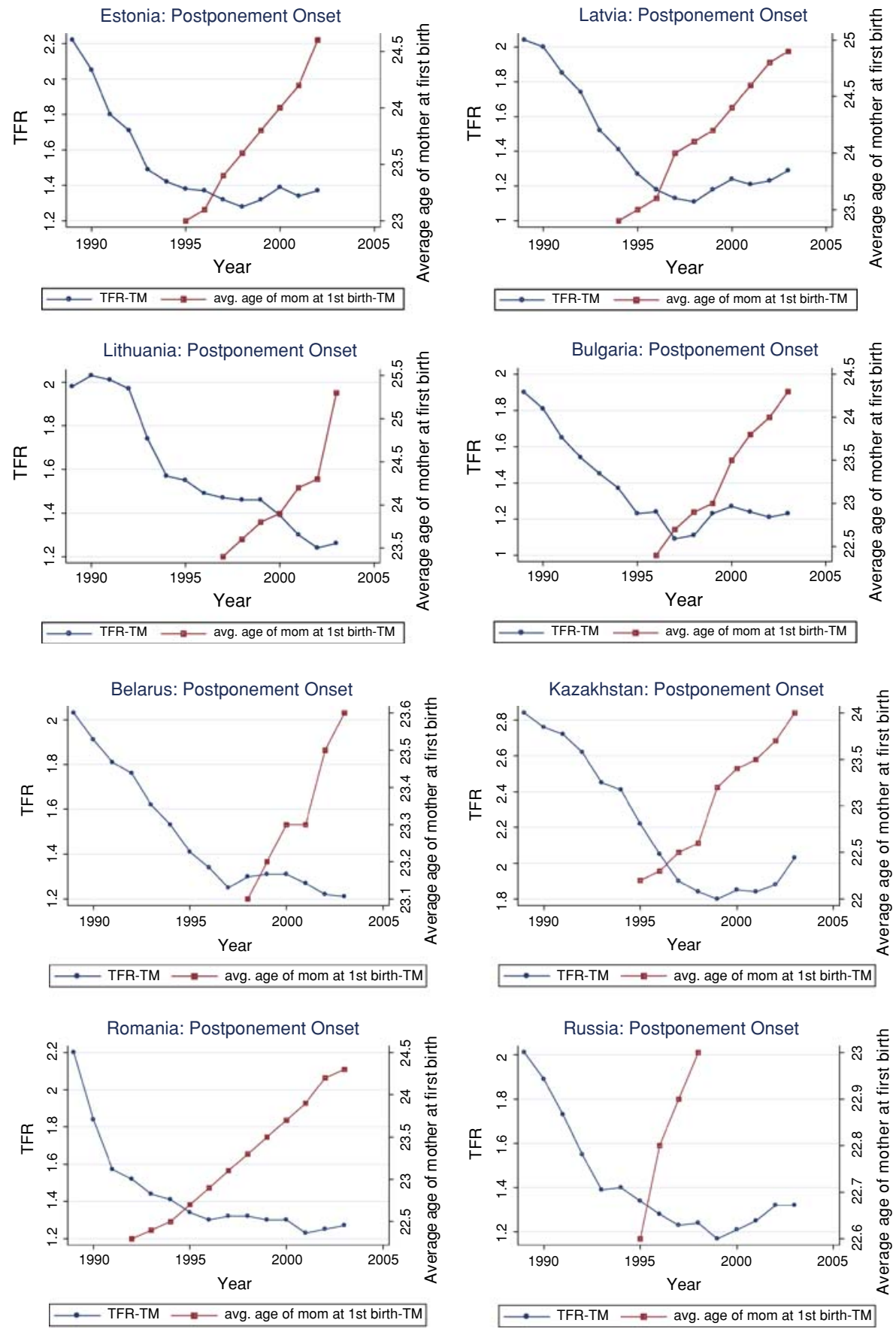

Fig. 9 Remaining countries 


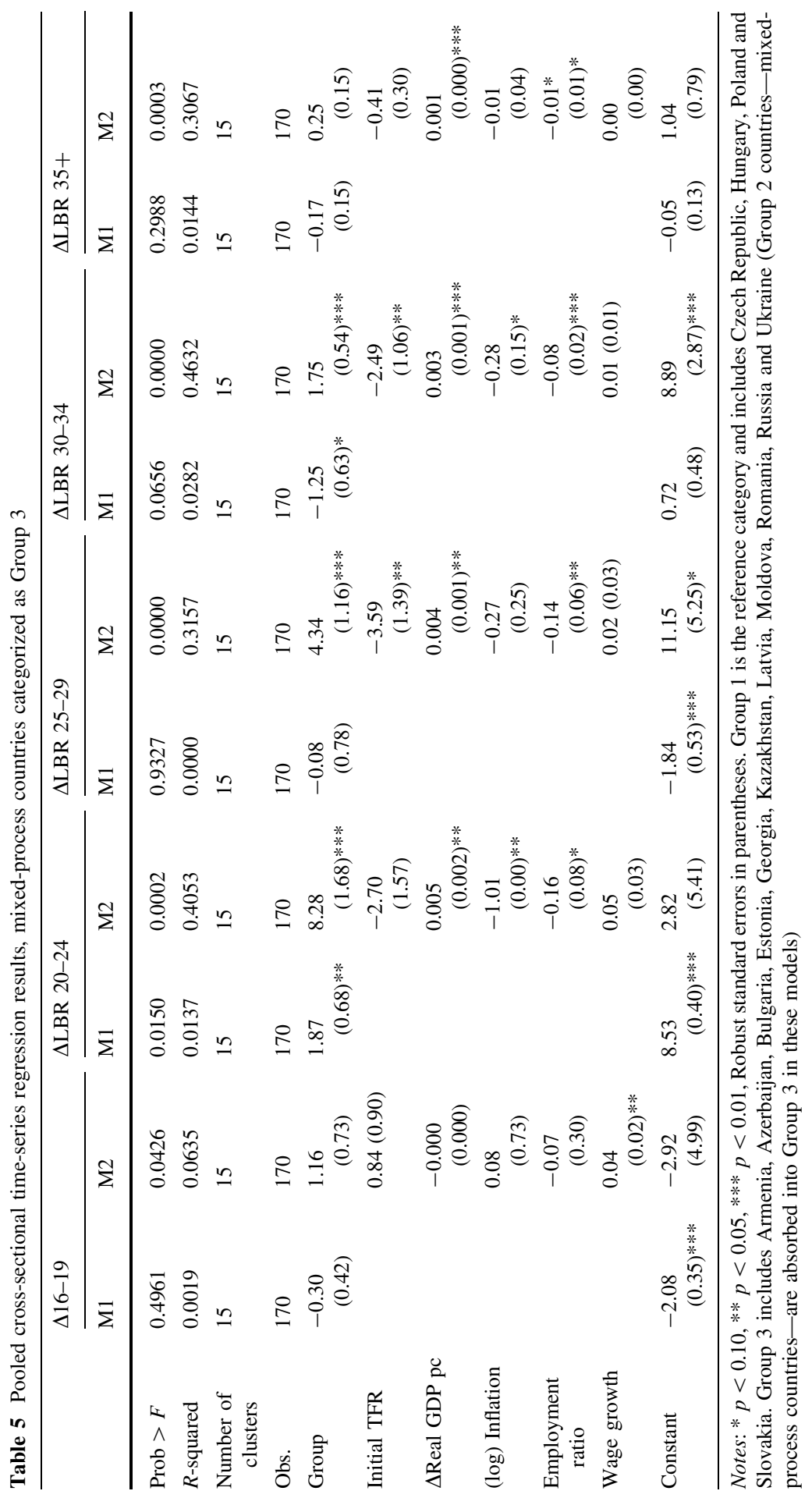




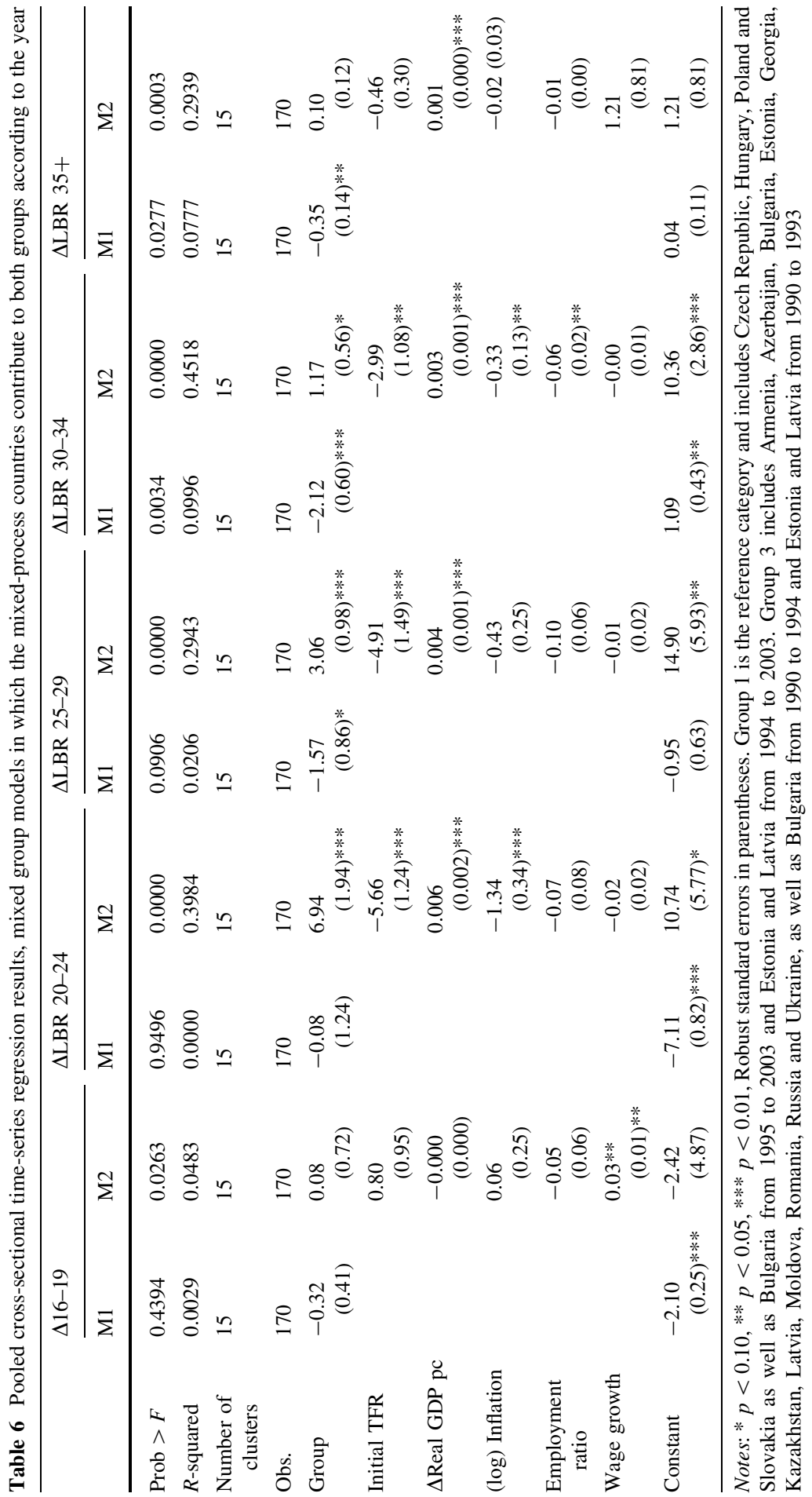


Table 7 Logistic regression results for postponement of childbirth, mixed-process countries categorized as Group 1

\begin{tabular}{lll}
\hline & \multicolumn{2}{l}{ Logistic regression postponement } \\
\cline { 2 - 3 } & M1 & M2 \\
\hline Prob $>\chi^{2}$ & 0.1490 & 0.0000 \\
Pseudo $R$-squared & 0.0323 & 0.4883 \\
Log pseudo likelihood & -92.999 & -49.177 \\
Obs. & 147 & 147 \\
Group & $0.42(0.25)$ & $6.25(4.41)^{* * * *}$ \\
Initial TFR & & $0.03(0.05)^{* *}$ \\
$\Delta$ Real GDP pc & & $1.01(0.00)^{* * *}$ \\
(log) Inflation & & $0.79(0.15)$ \\
Employment ratio & & $0.99(0.07)$ \\
Wage growth & & $1.01(0.02)$ \\
\hline
\end{tabular}

Notes: $* p<0.10$, ** $p<0.05$, *** $p<0.01$, Robust standard errors in parentheses. Group 1 is the reference category and includes Bulgaria, Czech Republic, Estonia, Hungary, Latvia, Poland and Slovakia. Group 3 includes Armenia, Azerbaijan, Georgia, Kazakhstan, Moldova, Romania, Russia and Ukraine (Group 2 countries-mixed-process countries-are absorbed into Group 1 in these models)

\section{References}

Becker, G. (1960). An economic analysis of fertility. In Demographic and economic change in developed countries, Universities-National Bureau of Economic Research Conference Series 11, NBER, Princeton, NJ, pp. 209-231.

Becker, G. (1981). A treatise on the Family. Cambridge, MA: Harvard University Press.

Bhaumik, S. K., \& Nugent, J. B. (2002). Does economic uncertainty have an impact on decisions to bear children? Evidence from Eastern Germany. William Davidson Institute Working Paper No. 491. SSRN from http://ssrn.com/abstract=323592.

Bhrolcháin, M., \& Dyson, T. (2007). On causation in demography: Issues and illustrations. Population and Development Review, 33(1), 1-36. doi:10.1111/j.1728-4457.2007.00157.x.

Billari, F., \& Kohler, H. P. (2004). Patterns of lowest-low fertility in Europe. Population Studies, 58(2), 161-176. doi:10.1080/0032472042000213695.

Blanchard, O. (1997). The economics of post-communist transition. Clarendon Lectures in Economics. New York: Oxford University Press.

Bongaarts, J., \& Feeney, G. (1998). On the quantum and tempo of fertility. Population and Development Review, 24(2), 271-291. doi:10.2307/2807974.

Bühler, C. (2004). Additional work, family agriculture, and the birth of a first or a second child in Russia at the beginning of the 1990s. Population Research and Policy Review, 23(3), 259-289. doi: 10.1023/B:POPU.0000034100.51781.d3.

Bühler, C., \& Philipov, D. (2005). Social capital related to fertility: Theoretical foundations and empirical evidence from Bulgaria. Vienna yearbook of population research 2005. Vienna: Austrian Academy of Sciences Press.

Cohen, J., Cohen, P., West, S., \& Aiken, L. (2003). Applied multiple regression/correlation analysis for the behavioral sciences (3rd ed.). Hillsdale, NJ: Lawrence Erlbaum Associates.

Cornia, G. A., \& Paniccià, R. (1998). The transition's population crisis: Nuptiality, fertility, and mortality changes in severely distressed economies. In M. Livi-Bacci \& G. de Santis (Eds.), Population and poverty in the developing world (pp. 217-249). Oxford: Clarendon press.

Council of Europe. (2003). Demographic yearbook 2003. Retrieved February 12, 2009, from http://www. coe.int/t/e/social_cohesion/population/demographic_year_book/2003_edition/04\%20Country\%20Data/ Default.asp\#TopOfPage. 
Easterlin, R. (1976). The conflict between aspirations and resources. Population and Development Review, 2(3/4), 417-425. doi:10.2307/1971619.

EBRD. (2003). Transition Report Update, 2003. London: European Bank for Reconstruction and Development.

Esping-Andersen, G., \& Przeworski, A. (2000). Quantitative cross-national research methods. In N. J. Smelser \& P. B. Baltes (Eds.), International Encyclopedia of the Social and Behavioral Sciences. New York: Elsevier Science.

European Foundation for the Improvement of Living and Working Conditions. (2005). Working conditions and gender in an enlarged Europe. Luxembourg: Office for Official Publications of the European Communities.

Fajth, G. (1999). Social security in a rapidly changing environment: The case of the post-communist transformation. Social Policy and Administration, 33(4), 416-436. doi:10.1111/1467-9515.00161.

Frejka, T. (2008). Determinants of family formation and childbearing during the societal transition in Central and Eastern Europe. Overview Chap. 5 in T. Frejka, T. Sobotka, J. M. Hoem, \& L. Toulemon (Eds.), Childbearing trends and policies in Europe. Demographic Research, Special Collection 7, Vol. 19(7), pp. 130-170, from http://www.demographic-research.org/volumes/vol19/7/.

Frejka, T., \& Sardon, J. P. (2003). Fertility trends and prospects in Central and Eastern Europe: The cohort perspective. Population of Central and Eastern Europe: Challenges and Opportunities. In European Population Conference, Warsaw, Poland, 26-30 August, 2003.

Friedman, D., Hechter, M., \& Kanazawa, S. (1994). A theory of the value of children. Demography, 31(3), 375-401.

Gerber, T., \& Cottrell, E. B. (2006). Fertility in Russia, 1985-2001. Insights from individual fertility histories. Paper presented at the Annual Meeting of the Population Association of America 2006, Los Angeles.

Gimpelson, V. (2001). The politics of labor-market adjustment: The case of Russia. In J. Kornai, S. Haggard, \& R. Kaufman (Eds.), Reforming the state: Fiscal and welfare in post-socialist countries (pp. 25-52). Cambridge, UK: University of Cambridge Press.

Gustafsson, S. (2002). Why do people want children? The 1934 Theory of the Myrdals and modern fertility theory. Paper presentation for the conference on Alva Myrdal's Questions to Our Time. March 6-8, 2002, Uppsala.

Hotz, V. J., Klerman, J. A., \& Willis, R. (1997). The economics of fertility in developed countries. In M. R. Rosenzweig \& O. Stark (Eds.), Handbook of population and family economics (pp. 275-347). Amsterdam: Elsevier Science B.V.

IMF World Economic Outlook Databases (2000, 2003). Available at IMF webpage http://www.imf.org/ external/ns/cs.aspx?id=28.

Inglehart, R. (1990). Culture shift in advanced industrial society. Princeton, NJ: Princeton University Press.

Kharkova, T., \& Andreev, E. (2000). Did the economic crisis cause the fertility decline in Russia: Evidence from the 1994 Microcensus. European Journal of Population, 16, 211-233. doi:10.1023/ A: 1026539832229.

Klugman, J., Micklewright, J., \& Redmond, G. (2002). Poverty in the transition: Social expenditure and the working-age poor. Innocenti Working Papers, No. 91, UNICEF, Florence, Italy.

Kohler, H. P., Billari, F., \& Ortega, J. (2002). The emergence of lowest-low fertility in Europe. Population and Development Review, 28(4), 641-680. doi:10.1111/j.1728-4457.2002.00641.x.

Kohler, H. P., \& Kohler, I. (2002). Fertility decline in Russia in the early and mid 1990s: The role of economic uncertainty and labour market crises. European Journal of Population, 18, 233-262. doi: 10.1023/A:1019701812709.

Kohlman, A., \& Zuev, S. (2001). Patterns of childbearing in Russia 1994-1998. Max Planck Institute for Demographic Research Working Paper 2001-018, July 2001.

Kreyenfeld, M. (2005). Economic uncertainty and fertility postponement: Evidence from German panel data. MPIDR Working Paper 2005-034.

Lesthaeghe, R., \& Moors, G. (2000). Recent trends in fertility and household formation in the industrialized world. Review of Population and Social Policy, 9, 121-170.

Lesthaeghe, R., \& Neidert, L. (2006). The second demographic transition in the United States: Exception or textbook example? Population and Development Review, 32(4), 669-698. doi:10.1111/ j.1728-4457.2006.00146.x. 
Lesthaeghe, R., \& Surkyn, J. (2002). New forms of household formation in Central and Eastern Europe: Are they related to newly emerging value orientations? Economic Survey of Europe 2002/1, New York and Geneva, Economic Commission for Europe, United Nations, pp. 197-216.

Lesthaeghe, R., \& Surkyn, J. (2004). When history moves on: The foundations and diffusion of a second demographic transition. Paper presented at the seminar on "Ideational perspectives on international family change", Population Studies Center, Institute for Social Research (ISR), University of Michigan, Ann Arbor. From http://sdt.psc.isr.umich.edu/pubs/online/WhenHistoryMovesOn_ final.pdf.

Lesthaeghe, R., \& van de Kaa, R. (1986). Twee demografische transities? In D. van de Kaa \& R. Lesthaeghe (Eds.), Bevolking: groei en krimp (pp. 9-24). Deventer: Van Loghum Slaterus.

Maddala, G., \& Wu, S. (1999). A comparative study on unit root tests with panel data and a new simple test. Oxford Bulletin of Economics and Statistics, 61(S1), 631-652. doi:10.1111/1468-0084.61.s1.13.

Maslow, A. (1954). Motivation and personality. New York: Harper and Row.

Myrdal, A., \& Myrdal, G. (1934). Crisis in the population question. Stockholm: Bonniers.

Perelli-Harris, B. (2005). The path to lowest-low fertility in Ukraine. Population Studies, 59(1), 55-70. doi:10.1080/0032472052000332700.

Perelli-Harris, B. (2006). The influence of informal work and subjective well-being on childbearing in post-Soviet Russia. Population and Development Review, 32(4), 729-753. doi:10.1111/ j.1728-4457.2006.00148.x.

Philipov, D., \& Kohler, H. P. (2001). Tempo effects in the fertility decline in Eastern Europe: Evidence from Bulgaria, the Czech Republic, Hungary, Poland, and Russia. European Journal of Population, 17, 37-60. doi:10.1023/A:1010740213453.

Philipov, D., Spéder, Z., \& Billari, F. (2006). Soon, later or ever? The impact of anomie and social capital on fertility intentions in Bulgaria (2002) and Hungary (2001). Population Studies, 60(3), 289-308. doi:10.1080/00324720600896080.

Ranjan, P. (1999). Fertility behaviour under income uncertainty. European Journal of Population, 15, 2543. doi:10.1023/A:1006106527618.

Rindfuss, R., Reed, J., \& St. John, C. (1978). A fertility reaction to a historical event: Southern white birth rates and the 1954 desegregation ruling. Science, 201(4351), 178-180. doi:10.1126/science.351806.

Rotariu, T. (2006). Romania and the second demographic transition. The traditional value system and low fertility rates. International Journal of Sociology, 36(1), 10-27. doi:10.2753/IJS0020-7659360102.

Shkolnikov, V., Andreev, E., Leon, D., McKee, M., Meslé, F., \& Vallin, J. (2004). Mortality reversal in Russia: The story so far. Hygiea Internationalis, 4(4), 29-80. doi:10.3384/hygiea.1403-8668.044129.

Shkolnikov, V., Cornia, G. A., Leon, D., \& Meslé, F. (1998). Causes of the Russian mortality crisis: Evidence and interpretations. World Development, 26(11), 1995-2011. doi:10.1016/S0305750X(98)00102-8.

Sobotka, T. (2002). Ten years of rapid fertility changes in the European post-communist countries: Evidence and interpretation. Population Research Centre Working Paper Series 02-1, July.

Sobotka, T. (2003). Re-emerging diversity: Rapid fertility changes in Central and Eastern Europe after the collapse of the communist regimes. Population, 58(4/5), 451-485. doi:10.2307/3271307.

Sobotka, T. (2004). Is lowest-low fertility in Europe explained by the postponement of childbearing? Population and Development Review, 20(2), 195-220. doi:10.1111/j.1728-4457.2004.010_1.x.

Sobotka, T., Zeman, K., \& Kontarova, V. (2003). Demographic shifts in the Czech Republic after 1989: A second demographics transition view. European Journal of Population, 19, 249-277. doi:10.1023/ A: 1024913321935 .

Spielauer, M., Kostova, D., Kotzeva, T., Jekova, V., \& Borissova, K. (2005). The contextual database of the generations and gender program in Bulgaria: Conceptual framework and an overview of the Bulgarian context concerning the central database topics. MPIDR WP 2005-2006, Max Planck Institute for Demographic Research, Rostock.

Thornton, A., \& Philipov, D. (2007). Developmental idealism and family and demographic change in Central and Eastern Europe. European Demographic Working Paper 3, Vienna: Vienna Institute of Demography of the Austrian Academy of Sciences.

Trans MONEE. (2004, 2006, 2007). Database, UNICEF IRC, Florence.

UN ECE. (2000). Fertility decline in the transition economies, 1989-1998: Economic and social factors revisited. Economic Survey of Europe 2000, No. 1. Economic Commission for Europe, UN, New York and Geneva.

van de Kaa, D. (1987). Europe's second demographic transition. Population Bulletin, 42(1), 1-57. 
van de Kaa, D. (2002). The idea of a second demographic transition in industrialized countries. Paper presented at the sixth welfare policy seminar of the national institute of population and social security, Tokyo, Japan, 29 January 2002.

Vishnevskii, A. (1999). The demographic potential of Russia. Russian Social Science Review, 40(4), 11.

Vishnevskii, А. (2008). НАСЕЛЕНИЕ РОССИИ 2006. (Population of Russia. 14th Annual Report, In Russian.) Demoscope Weekly, Moscow. Retrieved February 12, 2009, from http://demoscope. ru/weekly/knigi/ns_r06/sod_r.html.

World Bank. (2000). Making transition work for everyone: Poverty and inequality in Europe and Central Asia. Washington, DC: The World Bank.

Zakharov, S. (2008). Russian Federation: From the first to the second demographic transition. Demographic Research, 24(19), 907-972. doi:10.4054/DemRes.2008.19.24.

Zakharov, S., \& Ivanova, E. (1996). Fertility decline and recent changes in Russia: On the threshold of the second demographic transition. In J. DaVanzo (Ed.), Russia's demographic “Crisis”. Santa Monica, CA: RAND. 